\title{
Composites
}

\section{High-velocity impact deformation and perforation of fibre metal laminates}

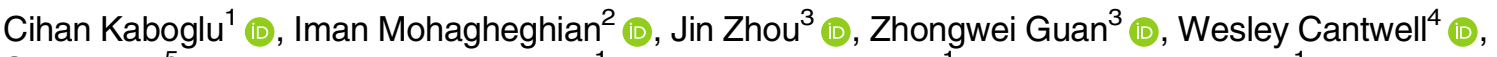 \\ Sabu John ${ }^{5}$ (1) Bamber R. K. Blackman ${ }^{1}$ (1) Anthony J. Kinloch ${ }^{1, \star}$ (1) and John P. Dear ${ }^{1, \star}$ (1) \\ ${ }^{1}$ Department of Mechanical Engineering, Imperial College London, South Kensington Campus, London SW7 2AZ, UK \\ ${ }^{2}$ Department of Mechanical Engineering Sciences, University of Surrey, Guildford, Surrey GU2 7XH, UK \\ ${ }^{3}$ School of Engineering, University of Liverpool, Liverpool L69 3GH, UK \\ ${ }^{4}$ Department of Aerospace Engineering, Khalifa University of Science and Technology, Abu Dhabi, United Arab Emirates \\ ${ }^{5}$ School of Engineering, RMIT University, Melbourne, VIC 3001, Australia
}

Received: 6 October 2017

Accepted: 27 November 2017

Published online:

11 December 2017

(C) The Author(s) 2017. This article is an open access publication

\section{ABSTRACT}

The quasi-static flexural and impact performance, up to projectile impact velocities of about $270 \mathrm{~m} \mathrm{~s}^{-1}$, of fibre metal laminates (FMLs), which consist of relatively thin, alternately stacked, layers of an aluminium alloy and a thermoset glass fibre epoxy composite, have been investigated. The effects of varying (a) the yield strength, tensile strength and ductility of the aluminium alloy layer, (b) the surface treatment used for the aluminium alloy layers and (c) the number of layers present in the FML have been studied. It was found that increasing the strength of the aluminium alloy increases the quasi-static flexural strength of the FML, providing that good adhesion is achieved between the metal and the composite layers. Further, increasing the number of alternating layers of the aluminium alloy and fibre composite also somewhat increases the quasi-static flexural properties of the FML. In contrast, increasing the strength of the aluminium alloy had relatively little effect on the impact perforation resistance of the FML, but increasing the number of alternating layers of aluminium alloy and fibre composite did significantly increase the impact perforation resistance of the FML. The degree of adhesion achieved between the layers had only a negligible influence on the impact perforation resistance.

Address correspondence to E-mail: a.kinloch@imperial.ac.uk; j.dear@imperial.ac.uk 


\section{Introduction}

Very different types of materials and structures have been manufactured to respond to the increasing demand for lightweight structures for the transport and energy sectors, e.g. the aerospace and wind energy industries. Amongst these, fibre metal laminates (FMLs) have attracted considerable attention because of their outstanding mechanical performance including excellent fatigue, fracture and impact properties [1-4]. FMLs are constructed by stacking and adhesively bonding together relatively thin layers of metals and fibre-reinforced polymeric composites. Typical thicknesses for the composite and metal layers are between 0.5 and $1 \mathrm{~mm}$. GLARE ${ }^{\circledR}$ is the most widely known FML and is used in the aerospace industry and consists of thin layers of a glass-fibre-reinforced plastic (GFRP) composite and an aluminium alloy. Various other metals and composites have also been explored for constructing FMLs. For the metal layer, lightweight alloys of aluminium [5], titanium [1, 6] and magnesium [7] have been employed. For the composite layer, various types of reinforcing fibres including aramid [8], carbon [9] and glass [10] fibres in a thermosetting or a thermoplastic matrix have been investigated.

FMLs have been the subject of many studies over a wide range of loading conditions including quasistatic bending and indentation [11, 12], blast loading [13], low-velocity impact [14] and high-velocity impact [15]. For example, Reyes and Cantwell [16] have conducted uniaxial tensile tests on thermoplastic-based FMLs, consisting of layers of aluminium alloy and glass-fibre-reinforced polypropylene. Tests on a number of different stacking sequences showed that the elastic modulus and ultimate strength of the FMLs followed a simple rule of mixtures. Increasing the volume fraction of the composite material in the FML resulted in an increase in the tensile strength, but a decrease in the tensile modulus [16]. Tensile tests conducted by Carrillo and Cantwell [17] using a thermoplastic-matrix FML, based on a self-reinforced polypropylene composite, indicated that such a FML gave a higher strength than simply a self-reinforced polypropylene thermoplastic composite with a unidirectional orientation. When compared to a monolithic aluminium alloy plate, for the same areal dimensions, the FML typically possessed a higher ductility but a lower strength [17]. Carrillo and
Cantwell [17] have also performed quasi-static flexural tests using FMLs with different fibre orientations. The maximum stresses and strains at failure of the FML were found to be independent of the fibre orientation and were mainly dependent on the volume fraction of the metal layers present. Fracture mechanics tests were performed by Reyes and Cantwell [16] over a wide range of cross head displacement rates between 0.1 and $1000 \mathrm{~mm} \mathrm{~min}^{-1}$. They measured extremely high fracture energies (e.g. ca. $4.7 \mathrm{~kJ} \mathrm{~m}^{-2}$ ) for the FML, which remained relatively high in value even under very high-rate loading conditions. Dhaliwaz and Newaz [18] have investigated the effect of the stacking sequence in the FML on the flexural and failure behaviour of carbonfibre-reinforced epoxy and aluminium-alloy-layered FMLs. They concluded that there were improvements in the flexural stiffness by having the carbon fibre epoxy composite located at the outer sides of the FML, but that this configuration for the FML did lower the failure strain.

Airoldi et al. [11] have explored the behaviour of FMLs under indentation loads. They focussed on FMLs which consisted of one layer of glass fibre epoxy composite and two outer layers of aluminium alloy (Grade 2024-T3). The indentation tests were conducted using a steel indenter with a hemispherical tip and a diameter of $15 \mathrm{~mm}$. Non-destructive inspection, using an ultrasonic C-scan technique, was employed for a post-mortem examination of each specimen. They noted that delamination between the composite and metal interface can occur in the FML. Vlot [9] measured the quasi-static indentation performance of three FMLs (i.e. GLARE- $2^{\circledR}$ using glass fibres, ARALL- $2^{\circledR}$ using aramid fibres and CARE ${ }^{\circledR}$ using carbon fibres) where in all cases an aluminium alloy (Grade 2024-T3) was used for the metal layer. Vlot compared the results from the FMLs with those for a monolithic aluminium alloy plate (i.e. Grade 2024-T3) for the same mass per unit area of plate. The results suggested that the peak force was always higher for the monolithic aluminium alloy plate. Under loading, failure in the FMLs was first observed for the CARE ${ }^{\circledR}$ FML, followed by the ARALL- $2{ }^{\circledR}$ FML and finally the GLARE- ${ }^{\circledR}$ FML. In terms of stiffness, all the FMLs had a similar value to that of the monolithic aluminium alloy.

The performance of FMLs has also been investigated under impact loadings. In an experimental study, Langdon et al. [19] performed localised impact 
blast tests on thermoplastic-based FMLs, made of glass-fibre-reinforced polypropylene and relatively thick layers of aluminium alloy (Grade 2024-O). In this study, various types of FMLs were explored by changing the number of aluminium alloy and composite layers, with the total aluminium alloy volume fraction varying from ca. $18-44 \%$. Damage and failure modes involved multiple delaminations, largescale plastic deformation, fibre fracture and matrix cracking. Using the experimental data of Langdon et al. [19], Lemanski et al. [20] determined an analytical expression for the critical impulse for the onset of tearing this, and this was found to increase linearly with the thickness of the FML. (Tearing, in the context here, is defined as the plastic fracture of the rear aluminium alloy layer [i.e. non-impacted face] of the FMLs.) Sitnikova et al. [13] employed a finite element analysis to study the perforation failure of FMLs subjected to high-intensity blast impact loading. The results were validated against the experimental results of Langdon et al. [19]. Sitnikova et al. [13] found that their finite element model captured most failure modes of the FMLs under high strain rate loading, such as 'petalling' (where petalling is defined as the metal alloy tearing and being plastically deformed around a perforation hole to form petal-shaped features), fracture of the composite layers and multiple delaminations of the metal/composite interfaces.

Vlot [21] compared the impact response of GLARE$3^{\circledR}$ and ARALL- ${ }^{\circledR}$ FMLs with a monolithic aluminium alloy plate of the same mass. The behaviour of GLARE- ${ }^{\circledR}$ and ARALL- ${ }^{\circledR}$, which both employ an epoxy matrix, was also compared with a thermoplastic-based FML, which used carbon-fibre-reinforced poly(ether-ether) ketone (PEEK) as the composite layer. This research showed that the GLARE- $3^{\circledR}$ FML exhibited a superior performance compared to all the other FMLs. In a separate study, Vlot [9] also showed that the perforation energy of GLARE $^{\circledR}$ FML was found to be close to, or even better than, the monolithic aluminium alloy plates of the same areal density and significantly greater than that of the ARALL ${ }^{\circledR}$ and CARE ${ }^{\circledR}$ FMLs.

Low-velocity impact tests were performed on propylene-based FMLs by Carrillo and Cantwell [17] at a constant impact velocity of $5.2 \mathrm{~m} \mathrm{~s}^{-1}$. Different levels of impact energy (up to $8.1 \mathrm{~J}$ ) were achieved by changing the mass of the drop-weight carriage. These FMLs were found to offer a high relatively level of energy absorption, with damage occurring in the form of thinning of the aluminium alloy layers and fracture of the composite layers [17]. Santiago et al. [22] investigated both thermoplastic- and thermosetbased FMLs and found that, when subjected to impact loading, thermoplastic-based FMLs were able to absorb more energy compared to a thermosetbased FML with the same areal density. However, the thermoset-based FMLs offered superior performance in terms of a lower area of detectable damage. This was due to stronger adhesion acting at the metal/composite interface in the case of the thermoset-based FMLs.

Caprino et al. [23] investigated the effect of impact loading on the failure mechanisms in FMLs subjected to a low-velocity impact. The perforation resistance of the FMLs was found to be superior to that of the monolithic composites, but inferior to a monolithic aluminium alloy plate which had an equivalent thickness. Zhou et al. [5] compared the perforation response of FMLs based on three types of aluminium alloy under quasi-static indentation and low-velocity impact loading. They observed similar failure mechanisms under both types of loading, including plastic deformation in the metal layers, fibre fracture in the composite layers and limited delamination of the composite layers. The impact perforation energy of the FML was only $10-15 \%$ higher than the value measured under quasi-static loading. Zhu and Chai [14] also investigated the effects of the rate of loading and fibre type on the behaviour of FMLs manufactured using 2024-T3 aluminium alloy and glass-fibrereinforced epoxy composites. They noted that the response of the FMLs was very similar under both low-velocity and quasi-static loading. The FMLs manufactured from composite layers with unidirectional fibres gave a higher perforation resistance than the FMLs with woven fibres in the composite layers [14]. The effect of changing the constituent material on the low-velocity impact performance of FMLs was investigated by Asaee et al. [24]. A magnesium alloy was used for the metal layers and a filled polyurethane foam matrix containing glass fibres was employed for the composite layers. The glass fibres were either in the form of a 3D fibreglass weave (which consisted of two bidirectional woven fabrics, which were knitted together by a vertical series of fibreglass fibres or pillars) or a biaxial woven glass fibre. The number of layers of fibre composite present in the FMLs was either 4 layers, 7 layers or 16 layers. 
They concluded that FMLs manufactured using the 3D fibreglass composite layers showed the lowest extent of delaminated areas. In addition, increasing the number of glass-fibre layers in the FMLs reduced the level of deformation caused by the impactor, and therefore the FMLs with 16 layers of glass fibre composite offered the largest impact energy absorption capacity.

In contrast to the extensive literature considering the low-velocity impact of FMLs, relatively few studies have been reported concerning the response of FMLs under high-velocity impact. Vogelesang and Vlot [2] compared the energy needed to perforate GLARE $^{\circledR} 3$ FML, ARALL ${ }^{\circledR} 2$ FML, monolithic aluminium alloy (Grade 2024-T3) and a thermoplastic composite (PEEK reinforced with carbon fibres). Comparisons were made on the same areal density basis. The perforation energy needed was found to be significantly greater for the GLARE ${ }^{\circledR} 3$ FML compared to the other materials. Hoo Fatt et al. [25] performed high-velocity impact tests (up to a velocity of $220 \mathrm{~m} \mathrm{~s}^{-1}$ ) to determine the ballistic velocity (i.e. the impact velocity needed for perforation) of an FML consisting of layers of glass-fibre-reinforced epoxy composite and an aluminium alloy. Comparisons with a monolithic metal having the same areal density showed only a moderate increase in the ballistic limit for FMLs constituting of thin aluminium alloy layers (i.e. 1.5 and $1.9 \mathrm{~mm}$ in thickness). Analytical expressions were derived by Hoo Fatt et al. [25] which predicted the ballistic velocity to within $\pm 13 \%$ of the experimental results. The model suggested that the most of the energy absorbed (i.e. 84-92\%) was consumed in deforming the FML in bending and membrane plastic stretching mechanisms. Smaller levels of energy were absorbed in delamination of the metal/composite interface (i.e. 2-9\%) and tensile fracture of the glass fibre epoxy and aluminium alloy layers (i.e. 6-7\%). The high-velocity impact perforation resistance of thermoplastic-based FMLs was also investigated by Compston et al. [26] using projectiles with two different nose shapes, i.e. blunt and hemispherical. They observed that, for both nose shapes, the energy needed for perforation was greater than that for a monolithic aluminium alloy plate of the same weight. Abdullah and Cantwell [27] performed impact tests on polypropylenereinforced thermoplastic composites and aluminiumalloy-based FMLs. Two grades of aluminium alloy (Grade 2024) were used: annealed (O) and heat- treated (T3). The impact perforation energy and impact ballistic velocity to perforate the FMLs were estimated using the Reid-Wen [28] perforation model. The FMLs which were manufactured with layers of the aluminium alloy Grade 2024-T3, which possessed the higher tensile strength, were found to offer the superior resistance to impact perforation. However, the thickness of the aluminium layers in the two types of FML was slightly different: $0.6 \mathrm{~mm}$ for the 2024-O and $0.8 \mathrm{~mm}$ thickness for the 2024-T3 alloy. Although the comparison was made based on the value of the specific perforation energy, i.e. the impact perforation energy per unit mass, having different metal volume fractions can cause variations in the observed impact performance [29].

Noting the very limited amount of work on the high-velocity impact deformation and perforation of FMLs, the main aim of the present research is to perform an in-depth study of these aspects. We will employ various types of FMLs which consist of relatively thin, alternately stacked, layers of various grades of aluminium alloy and a woven glass-fibrereinforced plastic (GFRP) composite based on a thermoset epoxy matrix. The aims are to investigate the effects of: (a) the mechanical properties of the aluminium alloy layers, which are altered by the choice of grade for the aluminium alloy; (b) the adhesion at the aluminium alloy/composite layer interfaces, which is changed via the type of surface treatment used for the metal layers prior to manufacturing the FMLs; (c) the configuration used for the stacking sequence of the three different grades of aluminium alloy layers and GFRP composite layers in the FMLs; and (d) the overall thickness of the FML, which is changed by increasing the number of metal and composite layers in the FML. These effects will be studied firstly under quasi-static flexural-bending loading of the FMLs, where the flexural behaviour will be determined, and secondly under high-velocity impact loading, where the deformation behaviour and perforation resistance of the FMLs will be studied.

\section{Materials}

The FMLs investigated in this study were manufactured from a woven glass-fibre-reinforced plastic (GFRP) prepreg based on an epoxy matrix resin $\left(\mathrm{MTM}^{\circledR} 56\right.$ series, supplied by Umeco Ltd., UK) and 


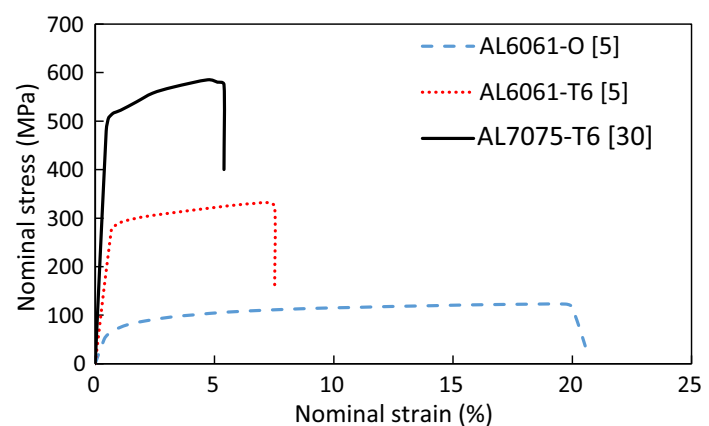

Figure 1 Stress-strain curves for the aluminium alloys investigated under quasi-static loading [5, 30].

three grades of aluminium alloy: 6061-O (annealed), 6061-T6 (heat-treated) and 7075-T6 (heat-treated), supplied by Aircraft Materials Ltd., UK. The stressstrain behaviour under quasi-static loading for the three different aluminium alloys is shown in Fig. 1. The 6061-O aluminium alloy exhibits the lowest strength but highest ductility amongst the three aluminium alloys used. Heat treatment of the 6061-O aluminium alloy, to give the grade 6061-T6 aluminium alloys, increases its strength, but lowers its ductility. The 7075-T6 aluminium alloy has the highest tensile strength and degree of strain-hardening behaviour, but the lowest ductility. Details of the various FML types used in the present study are listed in Table 1, and a schematic for the stacking sequence used for the FMLs is shown in Table 2. Using the same thickness of metal layer (i.e. $t=0.5 \mathrm{~mm}$ ) for all the three different grades of aluminium alloys in the FMLs causes the metal volume fraction to be in the range $49-60 \%$ for all the FMLs investigated (Table 1). The notation used in Table 1 gives the number of layers of aluminium alloy, $\mathrm{Al}$, (the grade)/and the number of layers of GFRP, G, used in the FML. The layers were always stacked alternately, and the outer layers used in the FMLs were always of the aluminium alloy.

Prior to manufacture of the FMLs, the aluminium alloys were surface treated, using a chromic acid etching process based on Alocrom 1000/1200, which is a chromate conversion coating (from Anodisers Runcorn Ltd., UK). This enhanced the interfacial adhesion between the aluminium alloy and the GFRP composite layers during the manufacture of FMLs. However, in order to investigate the effect of the degree of adhesion at the metal/composite layer interfaces on the mechanical behaviour of the FMLs, some FML panels were manufactured without any such prior surface treatment of the aluminium alloy, i.e. the aluminium alloy was simply used with its surface condition in the 'as received' state. The aluminium alloy and composite prepreg materials were then cut into sheets with sizes of $130 \mathrm{~mm} \times 130 \mathrm{~mm}$ or $150 \mathrm{~mm} \times 150 \mathrm{~mm}$. An appropriate number of composite prepreg and aluminium alloy sheets (Tables 1, 2) were alternately layered together and then placed in a press, and the assembly was heated to a temperature of $125^{\circ} \mathrm{C}$, at a rate of $1.5^{\circ} \mathrm{C} \mathrm{min}{ }^{-1}$,

Table 1 Notation and characteristics of the various types of FML studied

\begin{tabular}{|c|c|c|c|c|}
\hline Notation & Stacking configuration & $\begin{array}{l}\text { Thickness } \\
(\mathrm{mm})\end{array}$ & $\begin{array}{l}\text { Mass per unit } \\
\text { area }\left(\mathrm{kg} \mathrm{m}^{-2}\right)\end{array}$ & $\begin{array}{l}\text { Volume fraction } \\
\text { of Al alloy (\%) }\end{array}$ \\
\hline \multicolumn{5}{|c|}{ Aluminium alloy $(0.5+/-0.02 \mathrm{~mm}$ thick Grade $6061-\mathrm{O})$} \\
\hline $2 \mathrm{Al}(6-\mathrm{O}) / 1 \mathrm{G}$ & AL/GFRP/AL (2/1) & 1.8 & 3.77 & 59.5 \\
\hline $3 \mathrm{Al}(6-\mathrm{O}) / 2 \mathrm{G}$ & AL/GFRP/AL/GFRP/AL (3/2) & 3.0 & 6.28 & 53 \\
\hline $4 \mathrm{Al}(6-\mathrm{O}) / 3 \mathrm{G}$ & AL/GFRP/AL/GFRP/AL/GFRP/AL (4/3) & 4.0 & 8.68 & 50.8 \\
\hline \multicolumn{5}{|c|}{ Aluminium alloy $(0.5 \pm 0.02 \mathrm{~mm}$ thick Grade $6061-\mathrm{T} 6)$} \\
\hline $2 \mathrm{Al}(6-\mathrm{T}) / 1 \mathrm{G}$ & AL/GFRP/AL (2/1) & 1.8 & 3.85 & 56.5 \\
\hline $3 \mathrm{Al}(6-\mathrm{T}) / 2 \mathrm{G}$ & AL/GFRP/AL/GFRP/AL (3/2) & 3.0 & 6.58 & 51.9 \\
\hline $4 \mathrm{Al}(6-\mathrm{T}) / 3 \mathrm{G}$ & AL/GFRP/AL/GFRP/AL/GFRP/AL (4/3) & 4.0 & 9.27 & 49.3 \\
\hline \multicolumn{5}{|c|}{ Aluminium alloy $(0.5 \pm 0.02 \mathrm{~mm}$ thick Grade $7075-\mathrm{T} 6)$} \\
\hline $2 \mathrm{Al}(7-\mathrm{T}) / 1 \mathrm{G}$ & AL/GFRP/AL (2/1) & 1.8 & 4.11 & 55.9 \\
\hline $3 \mathrm{Al}(7-\mathrm{T}) / 2 \mathrm{G}$ & AL/GFRP/AL/GFRP/AL (3/2) & 3.0 & 6.75 & 51.4 \\
\hline $4 \mathrm{Al}(7-\mathrm{T}) / 3 \mathrm{G}$ & AL/GFRP/AL/GFRP/AL/GFRP/AL (4/3) & 4.0 & 9.51 & 49.6 \\
\hline
\end{tabular}

The GFRP layer was ca. $0.55 \mathrm{~mm}$ thick and consisted of three plies of woven prepreg glass-fibre-reinforced epoxy

The notation gives the number of layers of aluminium alloy, Al, (the grade)/and the number of layers of GFRP, G. The layers were always stacked alternately, and the outer layers used in the FMLs were always of the aluminium alloy 
Table 2 Stacking types of the FMLs

Stacking configuration

\begin{tabular}{|c|c|c|}
\hline $2 / 1$ & $3 / 2$ & $4 / 3$ \\
\hline $\begin{array}{l}\mathrm{AL} \\
\text { GFRP } \\
\mathrm{AL}\end{array}$ & $\begin{array}{l}\mathrm{AL} \\
\mathrm{GFRP} \\
\mathrm{AL} \\
\mathrm{GFRP} \\
\mathrm{AL}\end{array}$ & $\begin{array}{l}\text { AL } \\
\text { GFRP } \\
\text { AL } \\
\text { GFRP } \\
\text { AL } \\
\text { GFRP } \\
\text { AL }\end{array}$ \\
\hline
\end{tabular}

under a pressure of $0.4 \mathrm{MPa}$. Following consolidation, the FML panels were slowly cooled to below $60{ }^{\circ} \mathrm{C}$, before removal from the press. The $150 \mathrm{~mm} \times 150 \mathrm{~mm}$ square FML panels were cut into specimen beams with dimensions of $130 \mathrm{~mm} \times 45 \mathrm{~mm}$ for the quasi-static four-point bend tests. The FML panels of $130 \mathrm{~mm} \times 130 \mathrm{~mm}$ in size were used for the high-velocity impact tests.

\section{Experimental procedure}

\section{Quasi-static four-point flexural bend testing}

Quasi-static four-point flexural bend tests were performed, using a screw-driven testing machine (Instron 5800 series), to assess the mechanical performance of the different types of FML under flexural loading. The tests were performed according to ASTM D7264. Schematics of the test rig and the FML specimen are shown in Fig. 2. The ratio of the span of the outer loading pins to the thickness, $L_{2} / t$, has been shown [25] to have a significant influence on the failure mode of the specimen. Therefore, for all the bending tests, a constant value of span-to-thickness ratio of $20\left(L_{2} / t=20\right)$ was employed. This allows a direct comparison between the failure modes of the FML specimens with different thicknesses [31]. A constant value of 0.5 was also used for

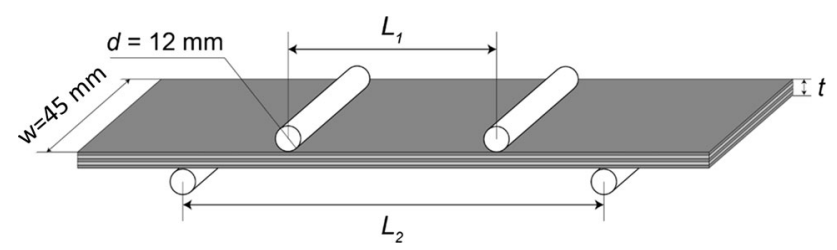

Figure 2 Schematic of the four-point flexural bend test. the ratio of the span of the inner loading pins, $L_{1}$, to the span of the outer loading pins, $L_{2}$, to give $L_{1} /$ $L_{2}=0.5$. The tests were performed using a constant cross head speed (i.e. loading-pin speed) of $1 \mathrm{~mm} \mathrm{~min}{ }^{-1}$. The tests were halted when the load dropped to approximately $50 \%$ of the maximum load.

\section{High-velocity impact testing}

High-velocity impact tests were conducted using the gas gun apparatus shown in Figs. 3 and 4 for two separate studies on the impact performance of the various types of FML. One study was concerned with the dynamic deformation resulting from a large aluminium alloy projectile, with a hemispherical front having a diameter of $25 \mathrm{~mm}$. Such a test simulates a bird strike or an impact by a large foreign body, e.g. large hailstones. The second study was designed to assess the perforation resistance of FMLs from smaller steel impactors, also with a hemispherical front (with a diameter of $10 \mathrm{~mm}$ ), to simulate impact from runway debris. The gas gun employed for both studies has a four-litre pressure vessel, with helium as the propellant, connected to a three-metre-long barrel by a fast-acting pneumatic valve. The velocity of the projectile was controlled by changing the pressure of the vessel. In the first study, 'Set-up I' was employed, see Fig. 3, for the large aluminium alloy impactors fired at below the ballistic perforation velocity to investigate the dynamic deformation behaviour. In the second study, 'Set-up II' was employed, see Fig. 4, using the smaller steel projectile to determine the ballistic velocity (i.e. the impact velocity needed for perforation of the FML), the perforation energy and the post-perforation response. 


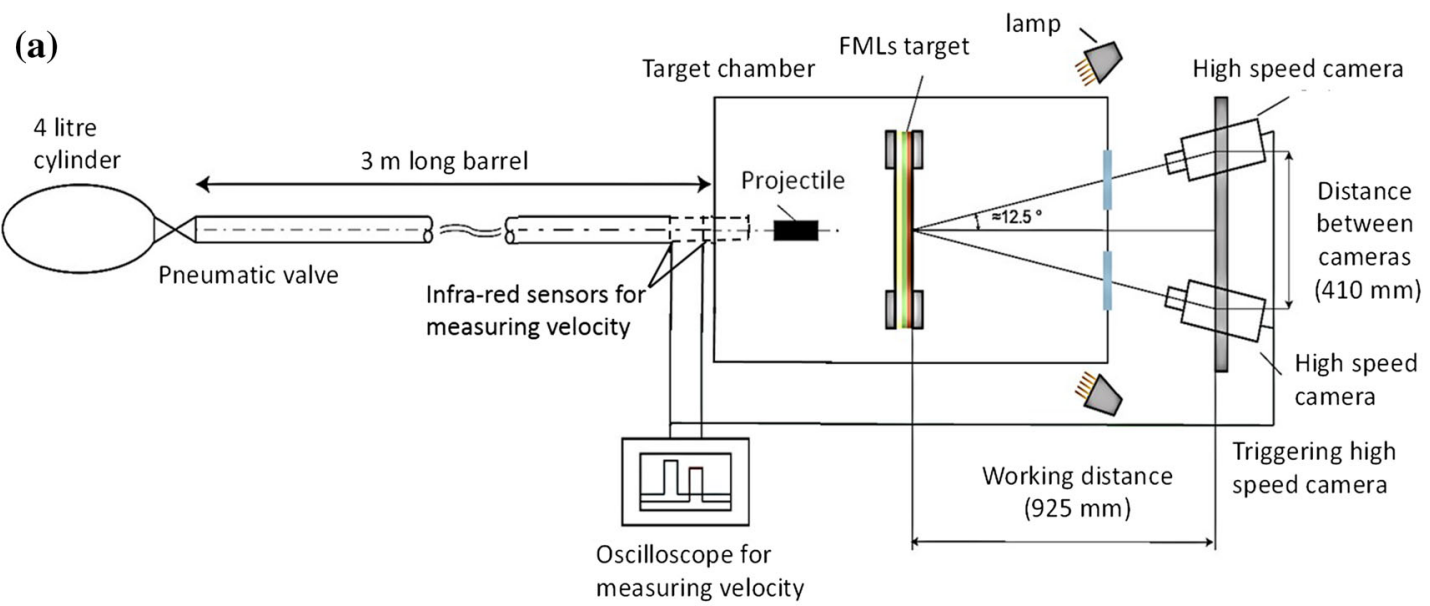

(b)

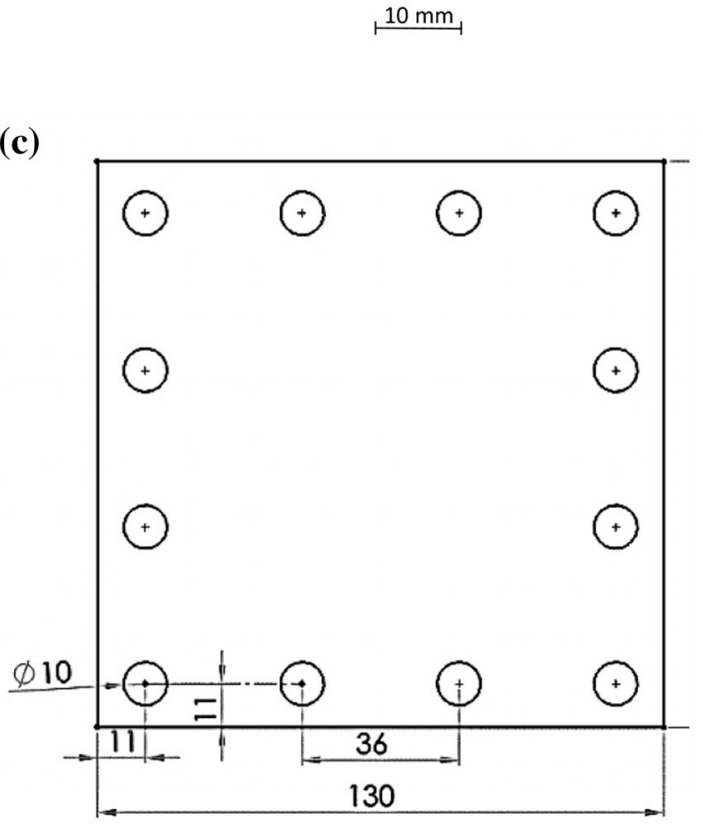

Figure 3 Set-up I: a gas gun for conducting high-velocity impact test employing the 3D digital image correlation (DIC) technique; b aluminium alloy projectile; $\mathbf{c}$ geometry of the sample (on the

For 'Set-up I', with the 25-mm-diameter aluminium alloy projectile, the high-speed 3D digital image correlation (DIC) technique was employed to observe the deformation of the back face of the rear (i.e. nonimpacted) aluminium alloy layer of the FML panel. The test set-up is similar to that described in detail by
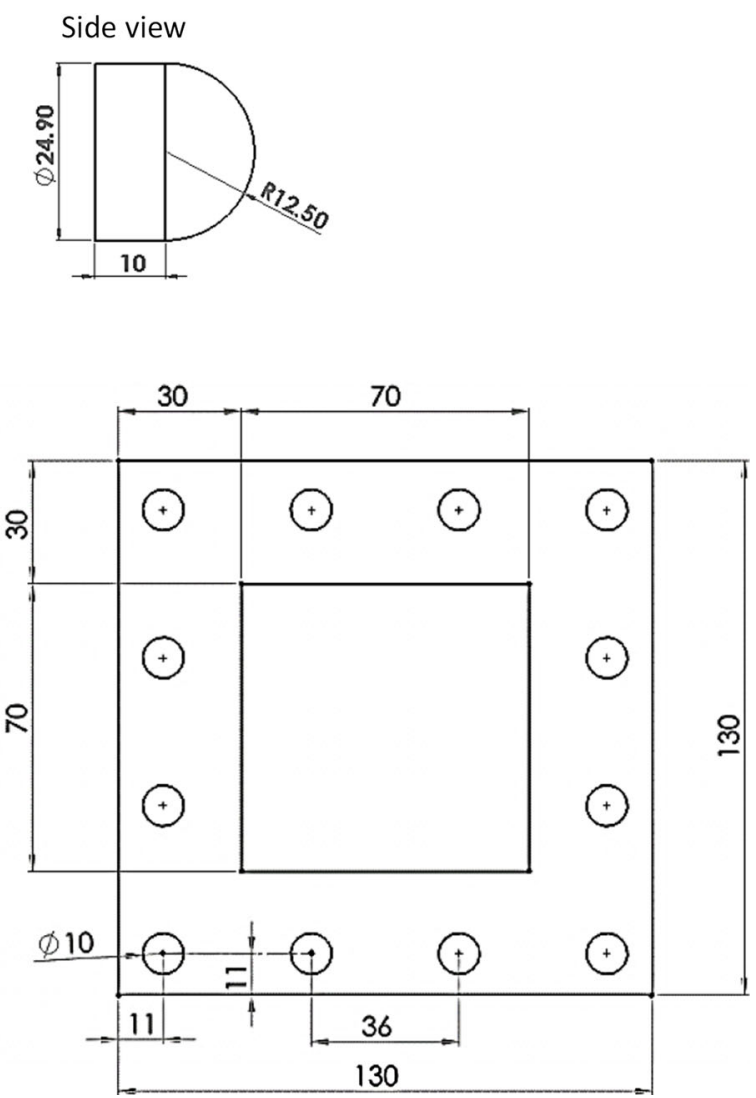

left-hand side) and clamp (on the right-hand side) (All dimensions in $\mathrm{mm}$ ) (The velocity measurement is in a vented section at the end of the barrel, with a barrel length of $3 \mathrm{~m}$ ).

Mohagheghian et al. [32] and was used to investigate the deformation behaviour of FMLs that were subjected to initial impact velocities where no perforation occurred. The experimental results obtained from the DIC were also employed to validate a finite element model for the deformation response of the 


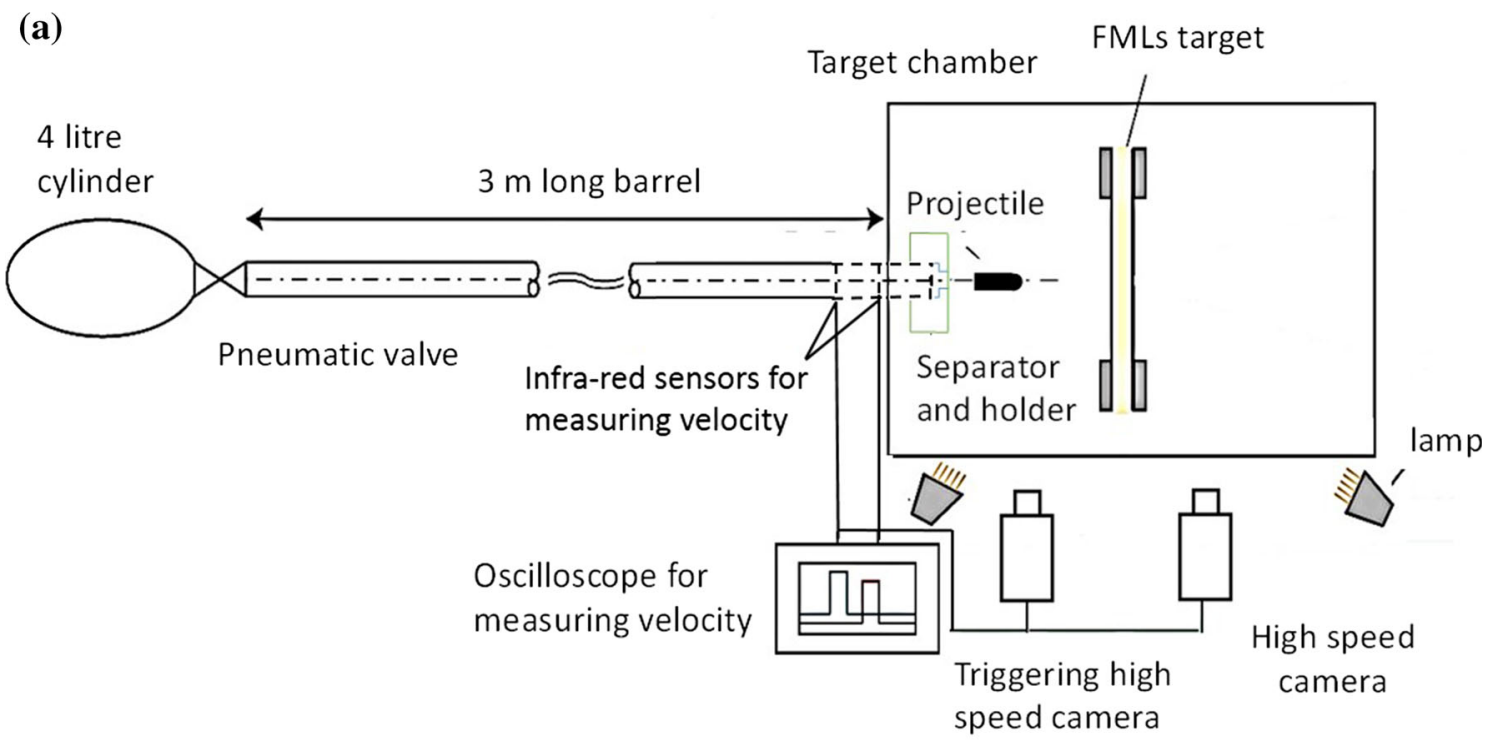

(b)
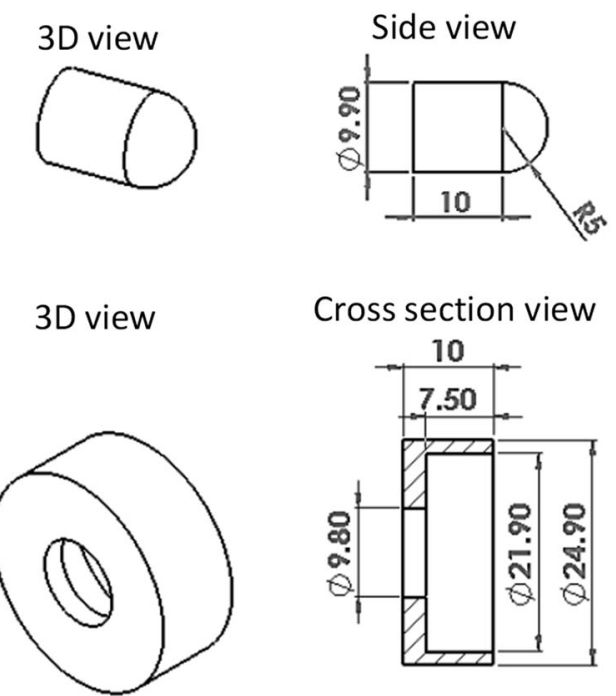

Cross section view

Fimensions in $\mathrm{mm}$ ) (The velocity measurement is in a vented section at the end of the barrel-barrel length $3 \mathrm{~m}$ ).
dimestic 4 Set-up II: gas gun used for the high-velocity impact perforation test; $\mathbf{b}$ schematic of the sabot and

FML panel. This will be presented in a future paper. The projectile and specimen dimensions used for 'Set-up I' are shown in Fig. 3b, c, respectively. Two high-speed cameras (i.e. 'Phantom Miro M/R/ LC310' cameras) were located pointing at the back face of the rear aluminium alloy of the FML target, separated by $410 \mathrm{~mm}$ and at a distance of $925 \mathrm{~mm}$ from the centre point of the target. The recording rate of the camera was 40000 frames per second, and they were triggered simultaneously by the signal generated from infrared sensors. A pair of identical 'Nikon' lenses, with a fixed focal length of $50 \mathrm{~mm}$, was used for both cameras. To illuminate the back face of the FML panel, two halogen lamps were employed, which were only turned on a few seconds before the experiment was initiated. The projectile was made of 7075-T6 aluminium alloy and had a diameter of $24.9 \pm 0.1 \mathrm{~mm}$ and a mass of $25.6 \pm 0.3 \mathrm{~g}$. A schematic of the projectile and its dimensions are shown in Fig. 3b. No plastic deformation of the projectile was observed after testing. The FML panels used for the impact testing were square flat plates with dimensions of $130 \times 130 \mathrm{~mm}$. The FML panels were fixed to a thick steel supporting plate of $20 \mathrm{~mm}$ in 
thickness using a metallic clamping plate with an opening of $70 \times 70 \mathrm{~mm}$ and a thickness of $15 \mathrm{~mm}$. Twelve 'M8'-sized bolts were used to fasten the clamping plate to the steel supporting plate. Schematic drawings of the specimen and the clamp are shown in Fig. 3c. For the 3D DIC measurements, the non-impacted side (i.e. the back face of the rear aluminium layer) of the FML was grit blasted before coating with a matt white acrylic paint. This was undertaken to enhance the degree of adhesion between the paint and the aluminium alloy surface; and the matt paint was used to reduce the amount of reflection from the surface of the FML panel. This was necessary in order to achieve good DIC results, especially where large deflections of the FML panel occurred. Finally, a random speckle pattern was generated on the white surface using a matt black marker to achieve the maximum contrast. For most tests, the level of adhesion was good for the speckle pattern, but if the paint did show signs of peeling, the test was invalidated and the results not included. The image size is $256 \times 256$ pixels, on an imaged area of the sample of $70 \times 70 \mathrm{~mm}$, giving a resolution (as related to area of the sample) of 13.4 pixels $/ \mathrm{mm}^{2}$. The size of the black speckles was measured to be 1.5-2.0 $\mathrm{mm}$. It should be noted that for images captured by the high-speed camera, speckles occupied 3-5 pixels, with a facet size of approximately 17-19 pixels for each displacement point, following the recommendations for the optimum speckle size [33].

For 'Set-up II', with the 10-mm-diameter steel projectile, as shown in Fig. 4, the aim was to investigate the ballistic velocity, as well as the post-perforation response of the FML panels, by measuring the projectile velocity after and before impacting the target (Fig. 4a). For this purpose, a cylindrical projectile with a hemispherical nose and a diameter of $10 \mathrm{~mm}$ was employed (Fig. 4b). The projectile was made of steel and had a mass of $8.0 \pm 0.07 \mathrm{~g}$. As for the tests conducted under 'Set-up I', no plastic deformation was observed in the projectile after impact. Since the diameter of the projectile (i.e. $10 \mathrm{~mm}$ ) was smaller than that of the gas gun barrel (i.e. $25 \mathrm{~mm}$ ), a sabot made of high-density polyethylene (HDPE) was used. The sabot was arrested at the end of the barrel by a stopper. The dimensions of the projectile, sabot and stopper are shown in Fig. $4 \mathrm{~b}$. The specimens were of the same size and employed the same clamping arrangement as used in the 3D DIC deformation studies (Fig. 3c). The initial velocity of the projectile was measured by a pair of infrared sensors located at the end of the barrel. Two highspeed cameras (i.e. 'Phantom Miro M/R/LC310' cameras) were located perpendicular to the travel direction of the projectile (Fig. 4a). One of the highspeed cameras was employed to measure the initial velocity of the projectile before impact. It should be noted that these velocity measurements were compared against those measured via the two infrared sensors. The velocity measurement from the two infrared sensors is in a vented section (last $50 \mathrm{~mm}$ ) at the end of the barrel (length $3 \mathrm{~m}$ ). The velocity was assumed constant in this vented section. This velocity was also checked by measuring velocity using the first high-speed camera, and the high-speed camera projectile velocity was within $\pm 2.5 \%$ of the projectile velocity measured using the two infrared sensors confirming the infrared sensor velocity measurement. The second camera was used to measure the residual velocity of the projectile after impact. A transparent safety chamber, made of thick polycarbonate panels, was used to confine the end of the barrel, as well as the target area. The absorbed energy is calculated from the difference between the residual and initial kinetic energies of the projectile. To determine the ballistic velocity, $V_{b l}$, for the 10 -mm-diameter steel projectile to perforate a series of different FML panels, impact experiments were performed with the initial velocities ranging from 116 to $268 \mathrm{~m} \mathrm{~s}^{-1}$. The residual velocity after penetration was plotted against the initial impact velocity of the projectile. A polynomial curve was fitted to the experimental results, based on the Lambert and Jonas relation [34], as given by:

$V_{r}=a\left(V_{i}^{p}-V_{b l}^{p}\right)^{1 / p}$,

where $V_{r}$ is the residual velocity of the projectile after perforation, $V_{i}$ is the initial impact velocity of the projectile, $V_{b l}$ is the ballistic velocity for the projectile to perforate the FML panel, and the terms $a$ and $p$ are fitting parameters. (It should be noted that when perforation occurred the projectile has a positive residual velocity, but when the projectile rebounds back from the front face of the aluminium alloy layer it has negative residual velocity.) The intersection of the polynomial curve with the initial impact velocity axis gives the ballistic velocity, $V_{b l}$, needed for perforation of the FML panel. 


\section{Results and discussion}

\section{Quasi-static flexural bend tests of the FMLs}

Table 3 gives a summary of the main findings from the quasi-static mechanical tests for the different types of FML that were examined, with some FMLs having had different surface treatments for the aluminium alloy layers prior to manufacture. Figures 6, 7 and 8 show the results obtained in more detail.

Figure 5 illustrates the results from the quasi-static flexural bend tests for two FML types, i.e. the 3Al(7T)/2G FML (Fig. 5a) and 4Al(7-T)/3G FML (Fig. 5b); see Table 1. Duplicates of these tests showed similar behaviour. As indicated in Table 1, these two types employ the high-strength 7075-T6 aluminium alloy. In both cases, the results are shown for FML specimens which were manufactured either with, or without, any surface treatment of the aluminium alloy layers prior to manufacture of the FML. (It should be noted that, because of the difference in the thickness of the two types, different values of $L_{2}$ were employed to maintain constant ratios of $L_{2} / t=20$ and $L_{1} / L_{2}=0.5$.) For both the $3 \mathrm{Al}(7-\mathrm{T}) / 2 \mathrm{G}$ and the $4 \mathrm{Al}(7-\mathrm{T}) / 3 \mathrm{G}$ FMLs, the response before the first load drop is bi-linear, i.e. a kink in the response was observed at a displacement of ca. $2 \mathrm{~mm}$. At this point, the FMLs start to deform plastically and this causes a decrease in the stiffness of the FMLs.

As can be seen in both Fig. 6a, b, the initial stiffness of the surface-treated FML specimens, where a chromic acid etch was employed for the aluminium alloy layers to give relatively good adhesion, is higher than for the FML specimens which were manufactured without any such surface treatment where relatively poor adhesion will be present at the (a)

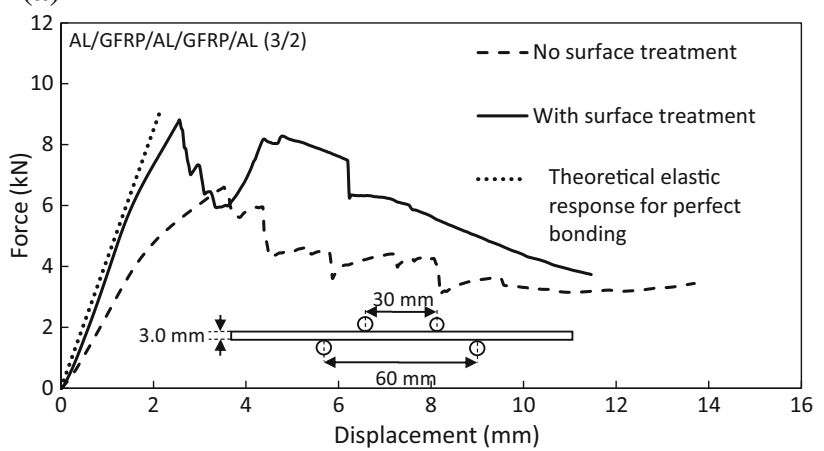

(b)

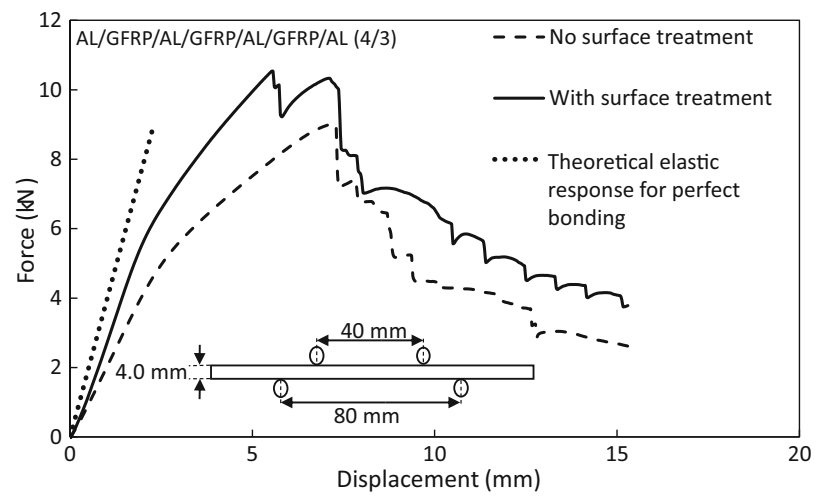

Figure 5 Quasi-static flexural response of the 7075-T6 aluminium alloy FML specimen beams, with and without surface treatment, under four-point flexural bending for two FML types: a the $3 \mathrm{Al}(7-\mathrm{T}) / 2 \mathrm{G} \mathrm{FML;} \mathbf{b}$ the $4 \mathrm{Al}(7-\mathrm{T}) / 3 \mathrm{G}$ FML.

aluminium alloy/GFRP interfaces. This observation arises since good adhesion, and hence good interfacial strength, see the solid lines in Fig. 5, in a multilayered structure permits an effective transfer of the shear stresses between the layers. Indeed, as can be seen in both Fig. 6a, b, the values of the theoretical

Table 3 Summary of results of the quasi-static flexural-bending FML specimen tests

\begin{tabular}{|c|c|c|c|c|c|c|}
\hline & Source of data & Surface treatment & Maximum force $(\mathrm{kN})$ & Energy absorption (J) & $\begin{array}{l}\text { Thickness } \\
(\mathrm{mm})\end{array}$ & Span length $(\mathrm{mm})$ \\
\hline $3 \mathrm{Al}(6-0) / 2 \mathrm{G}$ & Figure 8 & Yes & 3.5 & 17.1 & 3.0 & 60 \\
\hline $3 \mathrm{Al}(6-\mathrm{T}) / 2 \mathrm{G}$ & Figure 8 & Yes & 5.7 & 34.0 & 3.0 & 60 \\
\hline $3 \mathrm{Al}(7-\mathrm{T}) / 2 \mathrm{G}$ & Figure 8 & Yes & 8.7 & 55.5 & 3.0 & 60 \\
\hline $3 \mathrm{Al}(7-\mathrm{T}) / 2 \mathrm{G}$ & Figure 5 & No & 6.4 & 37.9 & 3.0 & 60 \\
\hline $4 \mathrm{Al}(7-\mathrm{T}) / 3 \mathrm{G}$ & Figure 5 & Yes & 10.1 & 65.9 & 4.0 & 80 \\
\hline $4 \mathrm{Al}(7-\mathrm{T}) / 3 \mathrm{G}$ & Figure 5 & No & 9.0 & 37.6 & 4.0 & 80 \\
\hline
\end{tabular}

Span-to-thickness ratio is constant at 20. (The energy absorption is determined from the area under the force-displacement curve up to a displacement of $9 \mathrm{~mm}$ ) 

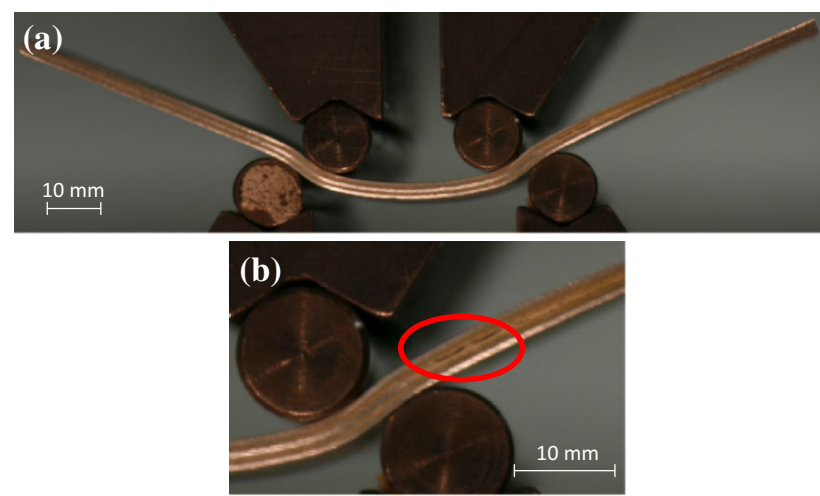

Figure 6 Photographs of the delamination between the layers in the $3 \mathrm{Al}(7-\mathrm{T}) / 2 \mathrm{G}$ FML specimen (using surface-treated aluminium alloy layers) that occurred during a quasi-static four-point flexural bend test at a cross head displacement of $4.5 \mathrm{~mm}$ : a the four-point bend specimen; $\mathbf{b}$ close-up showing the delamination region between the layers (circled in red).

stiffness of the FML specimens assuming perfect adhesion, see the dotted lines, are close in value to the stiffnesses of the specimens which had been subjected to the etching surface treatment. (The theoretical elastic stiffnesses of the FMLs were calculated from the second moment of inertia and beam theory [35] assuming perfect bonding at the interfaces of the

\section{With surface treatment Without surface treatment}

(a)
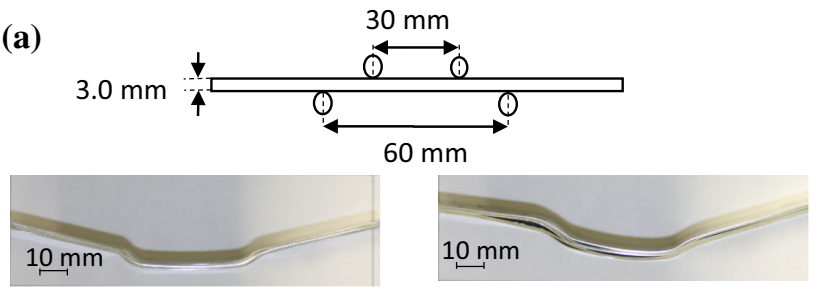

(b)
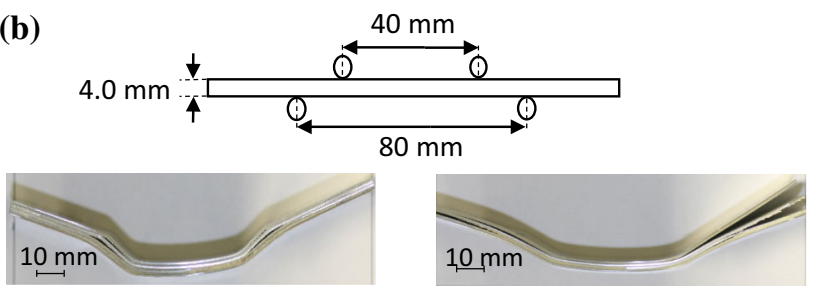

Figure 7 Photographs of the deformed FML specimen beams after having been subjected to the quasi-static four-point flexural bend test: a the $3 \mathrm{Al}(7-\mathrm{T}) / 2 \mathrm{G}$ specimen, with surface treatment (left-hand image) and without surface treatment (right-hand image) being used for the aluminium alloy layers; $b$ the $4 \mathrm{Al}(7$ T)/3G FML specimens, with surface treatment (left-hand image) and without a surface treatment (right-hand image) being used for the aluminium alloy layers. metal/composite layers.) Relatively weak interfacial strength, see the dashed lines, between the composite and aluminium alloy layers, as will occur in the absence of any chromic acid surface treatment, reduces the shear stress transfer between the layers and lowers the stiffness of the FML specimen.

Surface treatment of the aluminium alloy layers, which leads to a good level of adhesion at the metal/composite interfaces, not only results in an increase in the stiffness, but also improves the maximum load and energy absorption (i.e. the area under force-displacement curve up to a displacement of $9 \mathrm{~mm}$ in Fig. 5) recorded for the FML specimen, as may be seen in Fig. 6 and in Table 3. After the peak load has been attained, the force gradually reduces through a series of load drops. It is considered that delaminations of the metal/composite interfaces are responsible for these load drops. An example of the delaminations that occur can be seen in Fig. 6 for the $3 \mathrm{Al}(7-\mathrm{T}) / 2 \mathrm{G}$ FML specimen, which was photographed at a cross head displacement of approximately $4.5 \mathrm{~mm}$. A higher magnification view of the delaminated region is shown in Fig. $6 \mathrm{~b}$.

Photographs of different FML specimens, after testing, are shown in Fig. 7. Figure 7a shows the $3 \mathrm{Al}(7-\mathrm{T}) / 2 \mathrm{G}$ FML specimen, based on three aluminium alloy layers and two GFRP layers after testing. Figure $7 \mathrm{~b}$ shows the $4 \mathrm{Al}(7-\mathrm{T}) / 3 \mathrm{G}$ FML specimen, based on four aluminium alloy and three GFRP layers after testing. For each figure, for the left-hand image a surface treatment has been employed for the aluminium alloy prior to manufacturing the FML, whilst on the right-hand image no surface treatment was used. It may be seen that there is only very limited delamination in the area between the upper and lower rollers for specimens where a surface treatment has been employed for the aluminium alloy layers. In contrast, and as would be expected, far more extensive delamination is apparent in the FML specimens which were manufactured without any surface treatment of the aluminium alloy layers and where, therefore, only relatively poor adhesion had been achieved between the metal/composite layers. Indeed, it should be noted that delamination in these types of FMLs can extend to the free edges of the specimen; see Fig. $7 \mathrm{~b}$ (right-hand image).

Figure 8 shows the effect of varying the grade of the aluminium alloy used for the metal layers on the flexural-bending response of the FML specimens, made with three aluminium alloy and two GFRP 


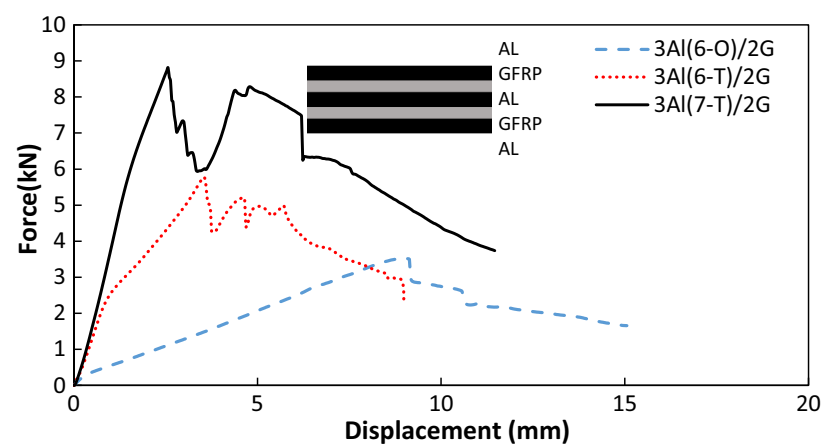

Figure 8 Quasi-static four-point flexural bend test results as a function of the grade of aluminium alloy used in the FML specimens. All the FML specimens have a 3/2 layer configuration, see the schematic, and the aluminium alloy layers were surface treated. The yield and tensile strengths of the different aluminium alloys are shown in Fig. 1.

layers: i.e. $3 \mathrm{Al}(6-\mathrm{O}) / 2 \mathrm{G}$ for the FML using the $6061-\mathrm{O}$ aluminium alloy, $3 \mathrm{Al}(6-\mathrm{T}) / 2 \mathrm{G}$ for the FML using the 6061-T6 aluminium alloy and $3 \mathrm{Al}(7-\mathrm{T}) / 2 \mathrm{G}$ for the FML using the 7075-T6 aluminium alloy (Table 1). The differences in the mechanical properties of the three aluminium alloys, see Fig. 1, result in a significant difference in the flexural response of the corresponding FML specimens. As shown in Fig. 5, the response prior to the first load drop is bi-linear for the $3 \mathrm{Al}(7-\mathrm{T}) / 2 \mathrm{G}$ and the $4 \mathrm{Al}(7-\mathrm{T}) / 3 \mathrm{G}$ FMLs. However, the location of the kink in the force versus displacement curves is different for the different FMLs and depends on the surface treatment. To further illustrate this point, in Fig. 8, the bi-linear load-deflection response is most notable for the $3 \mathrm{Al}(6-\mathrm{T}) / 2 \mathrm{G}$ and the $3 \mathrm{Al}(7-\mathrm{T}) / 2 \mathrm{G}$ FMLs, and occurs at a displacement of ca. 0.7 and ca. $2 \mathrm{~mm}$, respectively. The slope of the second linear region, which occurs after the kink, depends upon the yield strength of the aluminium alloy and is highest for the $3 \mathrm{Al}(7-\mathrm{T}) / 2 \mathrm{G}$ FML specimen, which is manufactured using the highest yield strength grade of aluminium alloy. Indeed, as may be seen from Table 3, the strength and energy absorption that were measured for this series of 3/2 FMLs are significantly higher for the FML specimen which was manufactured using the highest yield strength aluminium alloy (i.e. the $3 \mathrm{Al}(7-\mathrm{T}) / 2 \mathrm{G}$ FML) and employing a chromic acid etch surface treatment for the aluminium alloy prior to manufacture to give good adhesion at the metal/composite interfaces.

\section{High-velocity impact tests of the FML} panels

\section{Deformation of the FML panels during the high-velocity} impact test

In this section, the deformations of the face of the back face of the rear (i.e. non-impacted) aluminium alloy layer of the FML panels are reported from using the 3D DIC technique when the face of the front aluminium alloy layer of the panel is subjected to a high-velocity impact by a 25-mm-diameter aluminium alloy projectile. It will be recalled that this projectile, with dimensions of $130 \times 130 \mathrm{~mm}$ in size, impacts on a FML panel using 'Set-up I'; see Fig. 3. FML panels of $2 \mathrm{Al}(6-\mathrm{T}) / 1 \mathrm{G}$ and $4 \mathrm{Al}(7-\mathrm{T}) / 3 \mathrm{G}$ were tested using heat-treated aluminium alloy layers and using a chromic acid etch surface treatment, to give the best possible behaviour. Since the thicknesses of these two different FML panels are not the same, two different initial impact velocities were used in order to achieve the greatest out-of-plane displacement that could be attained without any perforation or damage occurring at the back face of the rear aluminium alloy of the FML panel.

As a detailed example, Fig. 9 shows the full-field out-of-plane displacement contour maps (Fig. 9a) during impact of the $2 \mathrm{Al}(6-\mathrm{T}) / 1 \mathrm{G}$ FML panel, both during the loading and the unloading phases. The deformation profile across the middle section of the plate is shown in Fig. 9b, and the out-of-plane displacement of the central point for the back face of the rear aluminium alloy layer is shown in Fig. 9c. This FML type has a configuration of two aluminium alloy outer layers and one middle composite layer and was subjected to an impact velocity of $54 \mathrm{~m} \mathrm{~s}^{-1}$. This FML panel had been fabricated using the chromic acid etch surface treatment and no signs of any delaminations were observed, so the maximum out-of-plane deformation of all the aluminium alloy layers for this FML specimen is ca. $8 \mathrm{~mm}$.

As another example, Fig. 10 gives the results for the $4 \mathrm{Al}(7-\mathrm{T}) / 3 \mathrm{G}$ FML panel, i.e. with four aluminium alloy layers and three composite layers, evaluated at a higher impact velocity of $97 \mathrm{~m} \mathrm{~s}^{-1}$. Again, a heattreated (i.e. high-strength) aluminium alloy, with a chromic acid etch surface treatment, was employed. It is of interest to note that the total thickness of the $4 \mathrm{Al}(7-\mathrm{T}) / 3 \mathrm{G}$ FML panel is more than double the thickness of the $2 \mathrm{Al}(6-\mathrm{T}) / 1 \mathrm{G}$ FML panel, as shown in 
Figure 9 Experimental results (obtained from 3D DIC) for the $2 \mathrm{Al}(6-\mathrm{T}) / 1 \mathrm{G}$ FML panel impacted at a velocity of $54 \mathrm{~m} \mathrm{~s}^{-1}$ for the: a full-field out-of-plane displacement; $\mathbf{b}$ out-of-plane displacement profile during loading and unloading (time increment between each profile is $0.025 \mathrm{~ms}$ ); c central, maximum, out-of-plane displacement as a function of time (The aluminium alloy layers were surface treated). (a)

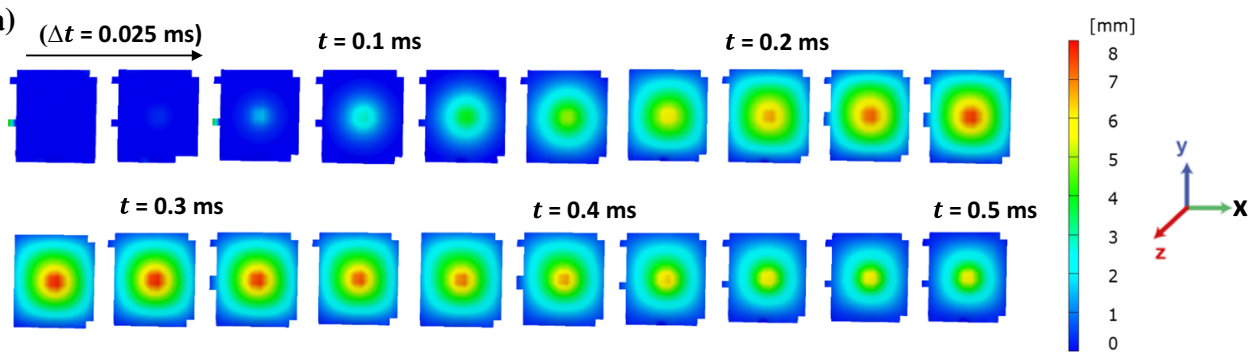

(b)
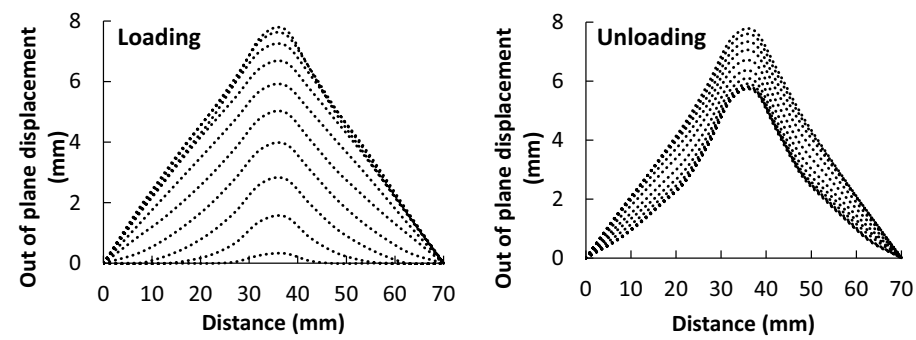

Profile of middle section of the plate

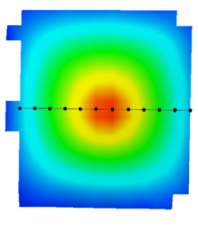

(c)

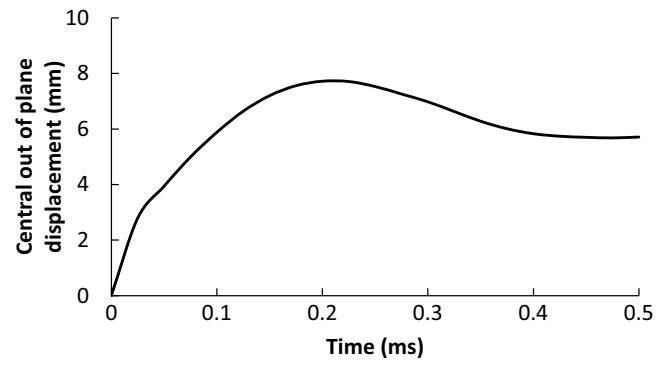

Table 1. However, upon using double the impact velocity, for the double thickness of the $4 \mathrm{Al}(7-\mathrm{T}) / 3 \mathrm{G}$ FML panel, the deformation response of the two FML panels was very similar. Again, there were no signs of delaminations and the maximum out-of-plane deformation of all the aluminium alloy layers for this FML panel is ca. $7 \mathrm{~mm}$.

\section{Perforation of the FML panels during the high-velocity impact tests}

For 'Set-up II', see Fig. 4, a series of impact tests were performed with the aim of investigating the ballistic velocity, perforation energy and the mechanisms of failure observed for the different FML panels. For this study, 10-mm-diameter steel projectiles were employed, since with these relatively small, hard projectiles perforation of the FML panel becomes more likely. The results are shown in Tables 4 and 5 and Figs. 11, 12, 13, 14, and are discussed below.

Firstly, the $3 \mathrm{Al}(6-\mathrm{O}) / 2 \mathrm{G}, 3 \mathrm{Al}(6-\mathrm{T}) / 2 \mathrm{G}$ and $3 \mathrm{Al}(7-$ T) $/ 2 G$ FML panels were studied in detail, since all these three FML panels have the same 3/2 layer configuration but were manufactured using different grades of surface-treated aluminium alloys. The results for the residual velocity, $V_{\mathrm{r}}$, plotted against the initial impact velocity, $V_{\mathrm{i}}$, of the projectile are shown in Fig. 11. Now, a positive value of the residual velocity in Fig. 11 indicates that full perforation of the FML panel has occurred, whilst a negative value indicates that the projectile rebounded from the front face of the aluminium alloy layer of the FML panel. A residual velocity of zero means that the projectile has been arrested in the FML panel. The marker size is not related to the uncertainty in measuring residual velocity, $V_{\mathrm{r}}$, and the uncertainty in the residual velocity, measured using the high-speed camera, was $\pm 2.5 \%$. The results in Fig. 11 are from a single experiment for each condition. The initial impact velocity, $V_{\mathrm{i}}$, was measured using the infrared sensors (and confirmed by high-speed camera). The best-fit curves of the Lambert and Jonas equation (Eq. 1) to the experimental results are also shown in Fig. 11, and the fitting parameters that are needed are listed in Table 4. From Table 4, it may be seen that the values of the ballistic velocity, $V_{\mathrm{bl}}$, for the projectile to perforate the FML panel, as well as the shape of the ballistic curves (Fig. 11), are very similar for all three types of FML panels, especially for the $3 \mathrm{Al}(6-\mathrm{T}) / 2 \mathrm{G}$ and $3 \mathrm{Al}(7-\mathrm{T}) / 2 \mathrm{G}$ FML panels. The ballistic velocity 
Figure 10 Experimental results (obtained from 3D DIC) for the $4 \mathrm{Al}(7-\mathrm{T}) / 3 \mathrm{G}$ FML panel impacted at a velocity of $97 \mathrm{~m} \mathrm{~s}^{-1}$ for the: a full-field out-of-plane displacement; $\mathbf{b}$ out-of-plane displacement profile during loading and unloading (time increment between each profile is $0.025 \mathrm{~ms}$ ); c central, maximum, out-of-plane displacement as a function of time (The aluminium alloy layers were surface treated).
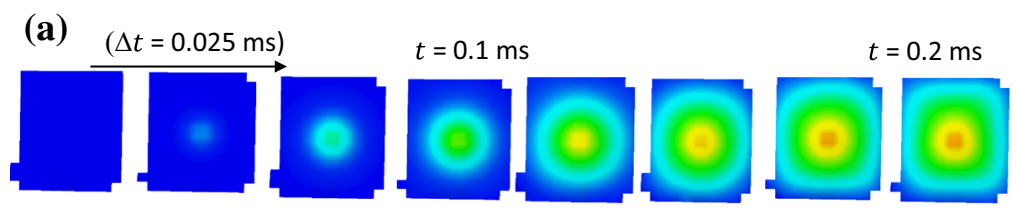

$t=0.3 \mathrm{~ms}$
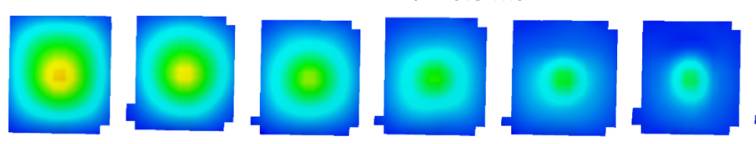

$t=0.4 \mathrm{~ms}$

(b)
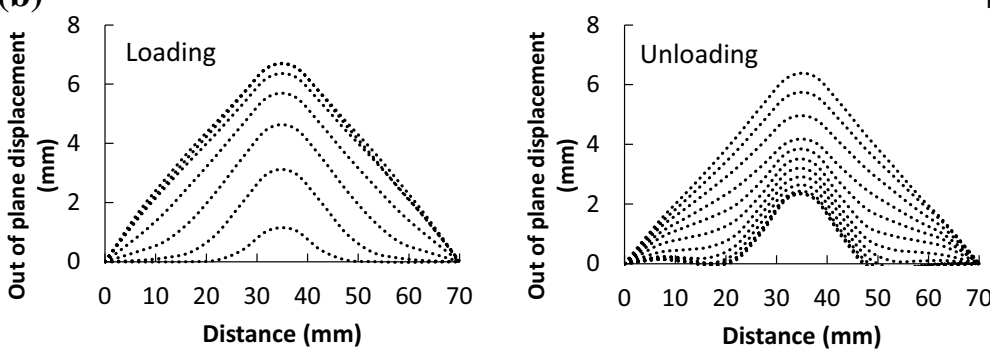

Profile of middle section of the plate

(c)

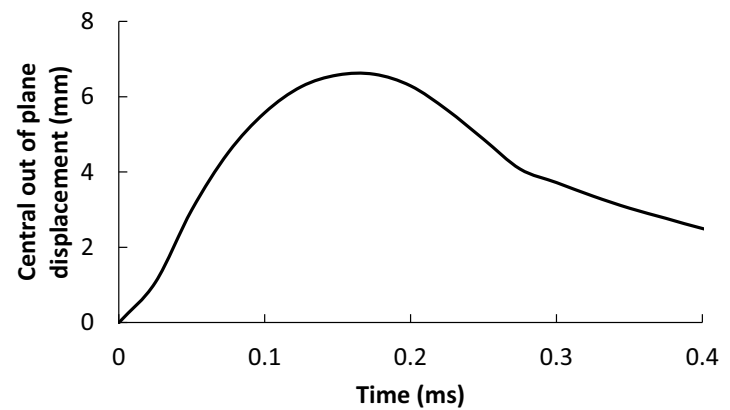

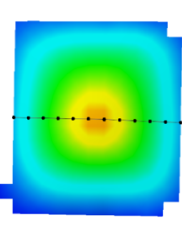

Middle point of the plate

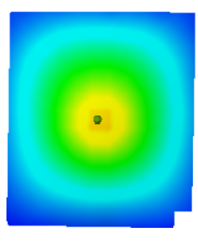

Table 4 Fitting parameters for the Lambert and Jonas equation

\begin{tabular}{llll}
\hline & $V_{\mathrm{bl}}\left(\mathrm{m} \mathrm{s}^{-1}\right)$ & $a$ & $p$ \\
\hline $3 \mathrm{Al}(6-0) / 2 \mathrm{G}$ & 118 & 0.8882 & 2.979 \\
$3 \mathrm{Al}(6-\mathrm{T}) / 2 \mathrm{G}$ & 128 & 1 & 2.064 \\
$3 \mathrm{Al}(7-\mathrm{T}) / 2 \mathrm{G}$ & 128 & 0.9309 & 2.322 \\
\hline
\end{tabular}

for the $3 \mathrm{Al}(6-\mathrm{O}) / 2 \mathrm{G} F M L$, i.e. with a $V_{\mathrm{bl}}=118 \mathrm{~m} \mathrm{~s}^{-1}$, is only slightly lower, by approximately $8 \%$, than that of the $3 \mathrm{Al}(6-\mathrm{T}) / 2 \mathrm{G}$ and $3 \mathrm{Al}(7-\mathrm{T}) / 2 \mathrm{G}$ FML panels, i.e. which both have a value of $V_{\mathrm{bl}}=128 \mathrm{~m} \mathrm{~s}^{-1}$. Thus, the values of the ballistic velocity, $V_{\mathrm{bl}}$, for the projectile to perforate the various types of FML panel are only somewhat higher for the FML panels manufactured using the aluminium alloy grades which have the higher values of yield and ultimate tensile strengths. This is in direct contrast to the considerable differences in the quasi-static flexural-bending response of these three types of FML; see Fig. 8. Further, again in contrast to the results shown in Fig. 11 and Table 4, it is of interest to note that significantly changing the mechanical properties of an aluminium alloy, via a heat treatment, is known to affect the ballistic performance of both thin [36] and thick [37, 38] monolithic aluminium alloy sheets. However, from the results shown in Fig. 11 and Table 4, the effect of the different mechanical properties of the different aluminium alloys used in the present study seems to be far less pronounced in affecting the ballistic behaviour of the resulting FMLs.

Secondly, to observe the impact damage, the FML panels were carefully cut in half and photographed. As an example, photographs of the rear aluminium alloy layer, as well as the cross section, of the 3Al(6O) /2G FML panels are shown in Fig. 12 for velocities ranging from 116 to $252 \mathrm{~m} \mathrm{~s}^{-1}$. At an impact velocity of $116 \mathrm{~m} \mathrm{~s}^{-1}$, the kinetic energy of the projectile was not quite sufficient to cause perforation of the FML panel by the projectile and plastic global bulging is seen on the rear layer of the aluminium alloy of the FML panel, which is accompanied by some fibre breakage and delamination of the metal/composite 
Table 5 Results of the perforation tests for all the various types of FML studied

\begin{tabular}{|c|c|c|c|c|}
\hline $\begin{array}{l}\text { FML panel } \\
\text { type }\end{array}$ & $\begin{array}{l}\text { Initial impact } \\
\text { velocity }\left(\mathrm{m} \mathrm{s}^{-1}\right)\end{array}$ & $\begin{array}{l}\text { Residual } \\
\text { velocity }\left(\mathrm{m} \mathrm{s}^{-1}\right)\end{array}$ & Failure mechanism & $\begin{array}{l}\text { Surface } \\
\text { treatment }\end{array}$ \\
\hline $2 \mathrm{Al}(6-0) / 1 \mathrm{G}$ & 267 & 243 & Global bulging, fibre breakage and delamination & Yes \\
\hline $3 \mathrm{Al}(6-0) / 2 \mathrm{G}$ & 116 & -6 & Global bulging, fibre breakage and some delamination & Yes \\
\hline $3 \mathrm{Al}(6-0) / 2 \mathrm{G}$ & 119 & 0 & Limited petalling, fibre breakage and some delamination & Yes \\
\hline $3 \mathrm{Al}(6-0) / 2 \mathrm{G}$ & 143 & 109 & Petalling, fibre breakage and delamination & Yes \\
\hline $3 \mathrm{Al}(6-0) / 2 \mathrm{G}$ & 172 & 125 & Petalling, fibre breakage and delamination & Yes \\
\hline $3 \mathrm{Al}(6-0) / 2 \mathrm{G}$ & 195 & 150 & Petalling, fibre breakage and delamination & Yes \\
\hline $3 \mathrm{Al}(6-0) / 2 \mathrm{G}$ & 214 & 181 & Moderate petalling, fibre breakage and delamination & Yes \\
\hline $3 \mathrm{Al}(6-0) / 2 \mathrm{G}$ & 252 & 216 & Increasing petalling, fibre breakage and delamination & Yes \\
\hline $4 \mathrm{Al}(6-0) / 3 \mathrm{G}$ & 265 & 210 & Extensive petalling, fibre breakage and delamination & Yes \\
\hline $2 \mathrm{Al}(6-\mathrm{T}) / 1 \mathrm{G}$ & 268 & 240 & Some petalling, fibre breakage and delamination & Yes \\
\hline $3 \mathrm{Al}(6-\mathrm{T}) / 2 \mathrm{G}$ & 120 & -25 & Global bulging and delamination & Yes \\
\hline $3 \mathrm{Al}(6-\mathrm{T}) / 2 \mathrm{G}$ & 178 & 57 & Petalling, fibre breakage and delamination & Yes \\
\hline $3 \mathrm{Al}(6-\mathrm{T}) / 2 \mathrm{G}$ & 247 & 211 & Moderate petalling, fibre breakage and delamination & Yes \\
\hline $4 \mathrm{Al}(6-\mathrm{T}) / 3 \mathrm{G}$ & 250 & 181 & Very extensive petalling, fibre breakage and delamination & Yes \\
\hline $2 \mathrm{Al}(7-\mathrm{T}) / 1 \mathrm{G}$ & 250 & 223 & Petalling and fibre breakage & Yes \\
\hline $3 \mathrm{Al}(7-\mathrm{T}) / 2 \mathrm{G}$ & 121 & 3 & Petalling and fibre breakage & Yes \\
\hline $3 \mathrm{Al}(7-\mathrm{T}) / 2 \mathrm{G}$ & 189 & 145 & Moderate petalling, fibre breakage and delamination & Yes \\
\hline $3 \mathrm{Al}(7-\mathrm{T}) / 2 \mathrm{G}$ & 236 & 190 & Extensive petalling, fibre breakage and delamination & Yes \\
\hline $4 \mathrm{Al}(7-\mathrm{T}) / 3 \mathrm{G}$ & 260 & 203 & Very extensive petalling, fibre breakage and delamination & Yes \\
\hline $3 \mathrm{Al}(7-\mathrm{T}) / 2 \mathrm{G}$ & 135 & 87 & Petalling, fibre breakage and moderate delamination & No \\
\hline $3 \mathrm{Al}(7-\mathrm{T}) / 2 \mathrm{G}$ & 193 & 140 & Petalling, fibre breakage and extensive delamination & No \\
\hline $3 \mathrm{Al}(7-\mathrm{T}) / 2 \mathrm{G}$ & 230 & 193 & Petalling, fibre breakage and extensive delamination & No \\
\hline
\end{tabular}

layers. Increasing the impact velocity to $119 \mathrm{~m} \mathrm{~s}^{-1}$ is sufficient to cause fracture in all the other layers and, at this velocity, the projectile is arrested in the target. (Note that sectioning of the FML was conducted after removing the projectile.) By further increasing the impact velocity, the deformation of the FMLs becomes more localised and leads to the formation of 'petals'. These arise from a plastic tearing fracture of the aluminium alloy layer, and their formation is accompanied by extensive plastic deformation of the metal layer. The number of petals was observed to vary between three to four petals according to the impact velocity employed: a greater number of petals were observed to arise as the initial impact velocity was increased.

Thirdly, Table 5 summarises the results from all the perforation tests for all the various types of FML panels that were examined and provides some additional information on the ballistic performance of the FML panels. From Table 5, it may be seen that the failure mechanisms change, especially the extent of the damage mechanisms, according to the initial impact velocity employed. Further, the mechanisms which were observed are especially dependent on whether the initial impact velocity was below, or above, the ballistic velocity. (See, for example, the descriptions of the failure mechanisms in Table 5 for the $3 \mathrm{Al}(6-0) / 2 \mathrm{G}$ FML panels when subjected to an increasing initial impact velocity.) In general, the damage in the FMLs may be associated with: (a) global bulging (i.e. global plastic deformation) of the panel which eventually leads to perforation, (b) perforation via a tearing plastic fracture and local plastic deformation of the aluminium alloy layers (i.e. 'petalling' occurs), and (c) fibre breakage and fracture in the composite layers and (d) delamination of the metal/composite interfaces which may accompany the perforation of the FML panel. Now, as may be observed from Table 5, the failure mechanisms of the different types of FML panels, where the aluminium alloy layers were surface treated prior to manufacture of the FMLs, were relatively similar to one other providing that perforation occurred, i.e. the initial impact velocity was greater than the ballistic velocity. However, the extent of the damage mechanisms was observed to increase as the initial impact velocity for any given FML type was increased. 
(a)

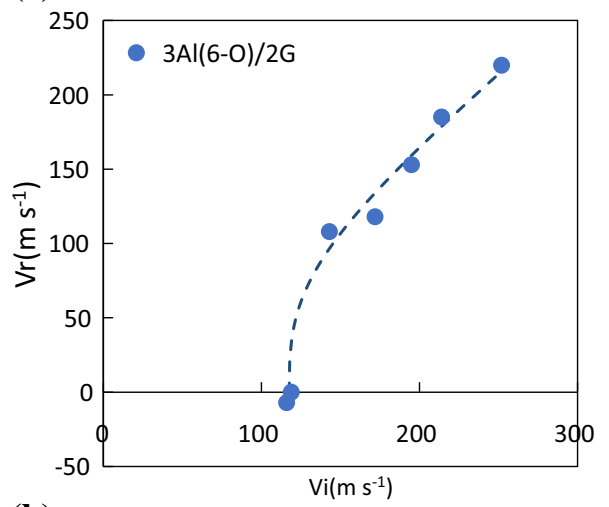

(b)

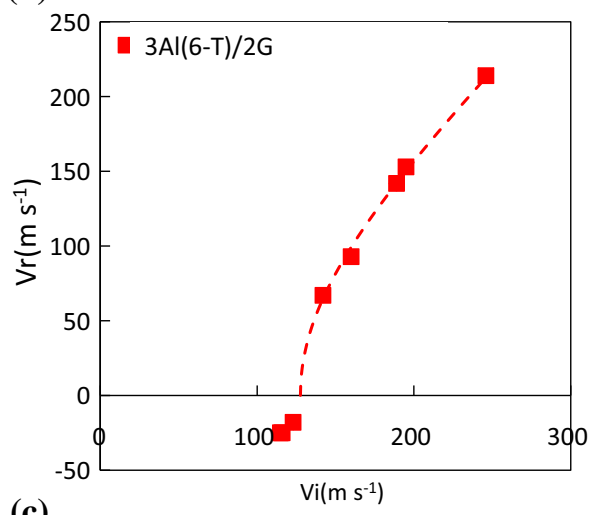

(c)

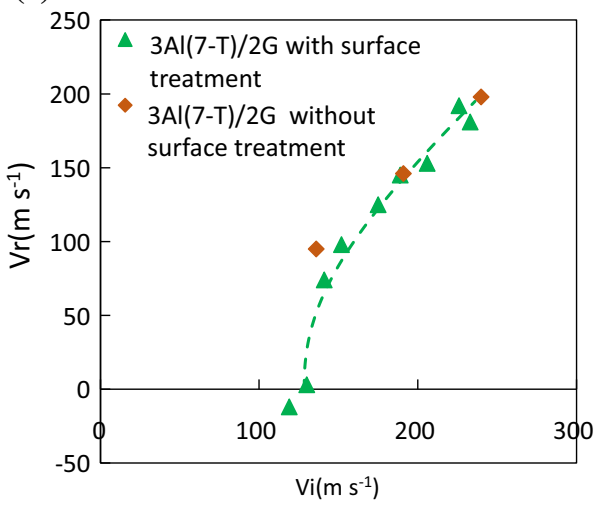

Figure 11 Residual velocity, $V_{\mathrm{r}}$, plotted against the initial velocity, $V_{\mathrm{i}}$, of the projectile for various FML panel types: a $3 \mathrm{Al}(6-\mathrm{O}) / 2 \mathrm{G}$ (using aluminium alloy Grade 6061-O); b 3 $\mathrm{Al}(6-\mathrm{T}) /$ $2 \mathrm{G}$ (using aluminium alloy Grade 6061-T6); c 3Al(7-T)/2G (using aluminium alloy Grade 7075-T6). (The $3 \mathrm{Al}(6-\mathrm{O}) / 2 \mathrm{G}$ and $3 \mathrm{Al}(6-$ T)/2G FMLs were manufactured using the chromic acid surface treatment for the aluminium alloy layers. The $3 \mathrm{Al}(7-\mathrm{T}) / 2 \mathrm{G}$ FMLs were manufactured with the aluminium alloy layers either with, or without, having been surface treated) (Uncertainty in measurement of residual velocity, $V_{\mathrm{r}}, \pm 2.5 \%$, from high-speed camera).

Fourthly, to investigate the effect of the degree of adhesion between the aluminium alloy and composite layers, three panels were also tested for the

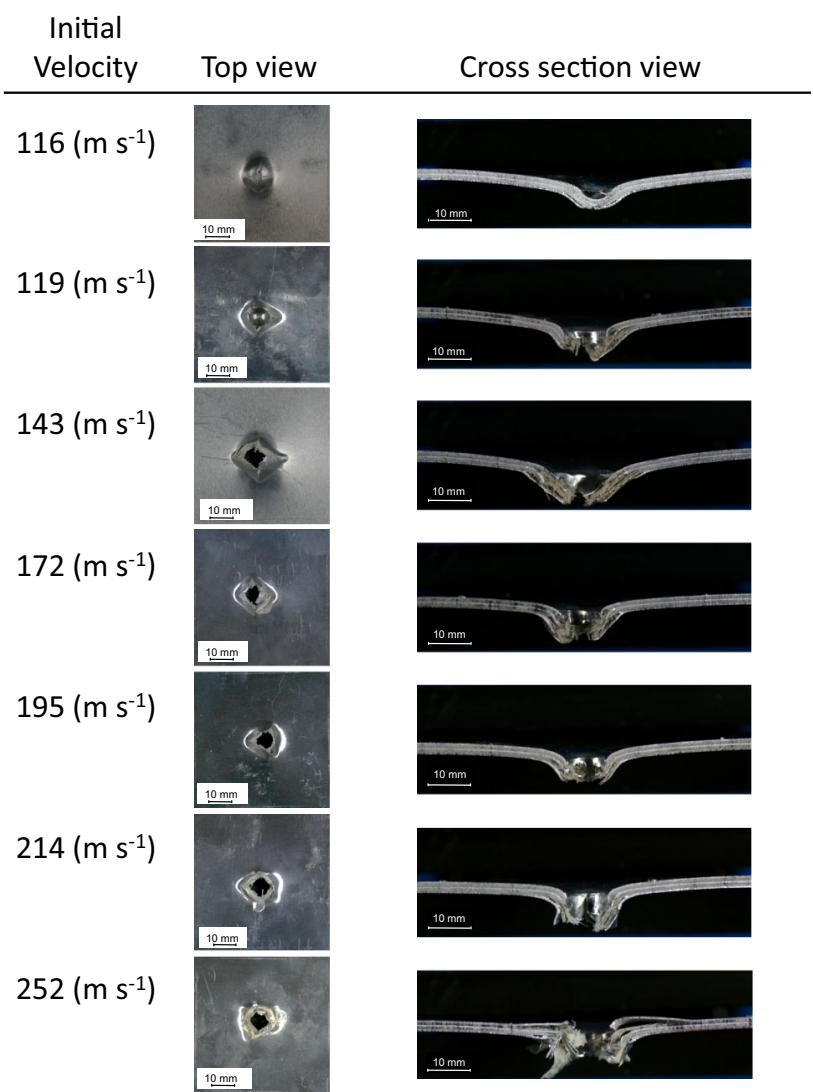

Figure 12 Photographs of perforated $3 \mathrm{Al}(6-\mathrm{O}) / 2 \mathrm{G}$ FML panels (i.e. a FML with a $3 / 2$ configuration and using surface-treated aluminium alloy Grade 6061-O) as a function of increasing the initial impact velocity. (A top view of the rear aluminium alloy layer and a cross-sectioned view of the FML panel are shown).

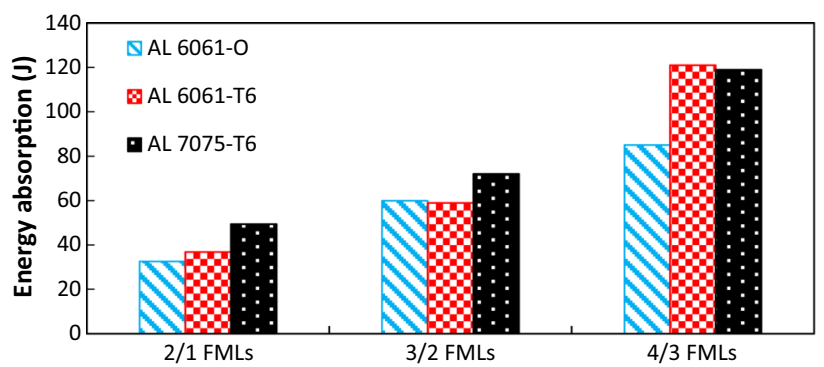

Figure 13 Effect of increasing the thickness of the FML panel on the high-velocity energy absorption for FML panels using various grades of surface-treated aluminium alloy layers at the highest impact velocity of ca. $250 \mathrm{~m} \mathrm{~s}^{-1}$. (Uncertainty in the measurement of the energy absorption is $\pm 5 \%$ from uncertainty in the residual velocity, $V_{r}, \pm 2.5 \%$, the high-speed camera measurements).

3Al(7-T)/2G FML type where no surface treatment was used for the aluminium alloy layers; see Table 5 . Now, it was observed that when a surface treatment was used for the aluminium alloy prior to 


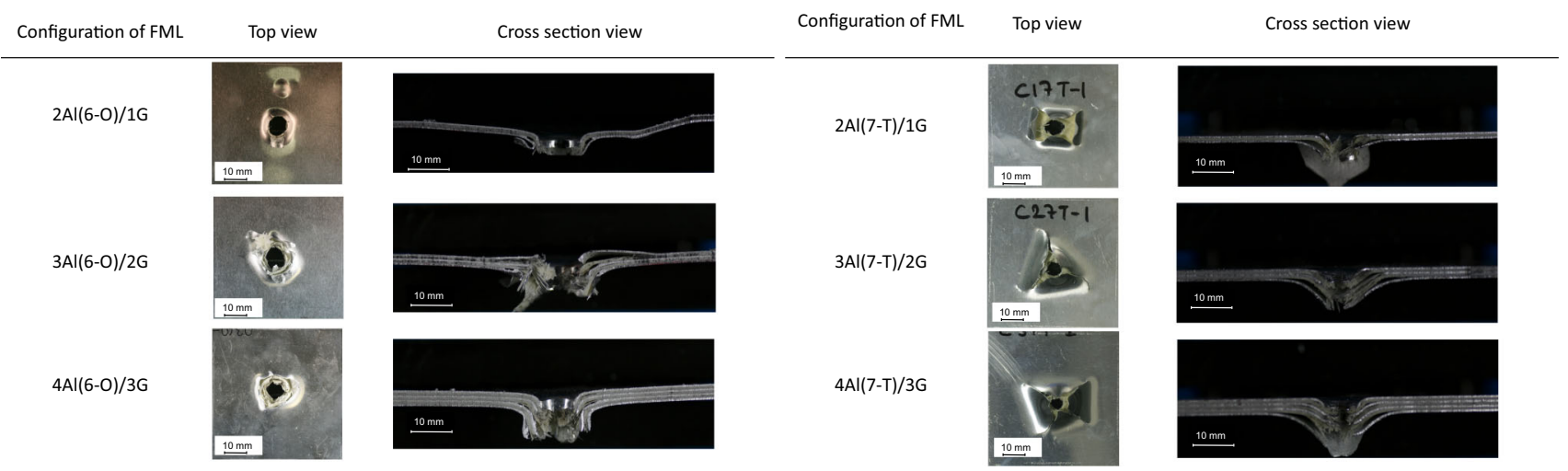

Figure 14 Comparison between the damage after impact in FMLs with various thicknesses using Grade 6061-O and Grade 7075-T6 aluminium alloys at the highest impact velocity of ca. $250 \mathrm{~m} \mathrm{~s}^{-1}$.

manufacture of the FML, to give good interfacial adhesion of the layers, the delamination between the aluminium alloy and the composite layers was limited to the areas close to the impacted zone. However, more extensive delamination was observed in the 3Al(7-T)/2G FML panels when no surface treatment was employed. Nevertheless, for velocities well above the ballistic velocity, no significant differences in the residual velocity were observed between the FML panels whether the aluminium alloy layers were, or were not, surface treated.

Fifthly, Fig. 13 shows the effect of increasing the thickness of the FMLs, by increasing the number of layers of aluminium alloy and GFRP composite in the FML panel, on the energy absorption of the FML, as well as the effect of the grade of aluminium alloy employed. (The energy absorption may be calculated from the difference in the kinetic energy of the projectile just before and just after perforation of the FML panel has occurred.) The FML types studied are: 2/1, $3 / 2$ and $4 / 3$ (Tables 1,2 ). The thickness increased from $t=1.74 \pm 0.06 \mathrm{~mm}$ for the 2/1 FML types, to $t=2.88 \pm 0.04 \mathrm{~mm}$ for the $3 / 2$ FML types, and to $t=4.00 \pm 0.05 \mathrm{~mm}$ for the $4 / 3 \mathrm{FML}$ types. These performance data, in Fig. 13, relate to the highest impact velocity of ca. $250 \mathrm{~m} \mathrm{~s}^{-1}$ which far exceeded the ballistic limit, see Table 4 , and therefore perforation of the FML panels was observed in all the experiments. Increasing the thickness and number of layers of the FML panel clearly results in a significant increase in the energy absorption. As a secondary effect, the energy absorption may, in some instances, be somewhat higher as the yield strength and ultimate tensile strengths of the aluminium alloy layer are increased, via the appropriate choice of the grade of the aluminium alloy layers employed in the FML panel. From studying the failed FML panels, these observations were considered to arise from a larger contribution to the energy absorption through (a) a tearing plastic fracture and local plastic deformation of the aluminium alloy layers (i.e. 'petalling') and (b) fibre breakage and fracture of the GFRP layers which accompanied the perforation of the FML panel. Indeed, these mechanisms were observed to be far more extensive in nature as the thickness of the FML panels was increased. Figure 14 shows these effects for the different thicknesses of FML panels, with low-strength aluminium alloy on the left and high-strength aluminium alloy on the right. Notable is the reduced deformation of the aluminium layers for the high-strength aluminium alloy, but energy absorption is still increased. Increasing the number of composite and metallic layers is beneficial in terms of energy absorption with plastic tearing fracture and petalling of the aluminium alloy layers and fibre breakage, delamination and fracture of the GFRP layers.

\section{Conclusions}

In the present study, the effects of varying the mechanical properties of the aluminium alloy layer, and the number of aluminium alloy and GFRP composite layers, in fibre metal laminates (FMLs) have been investigated. Further, the degree of adhesion acting at the metal/composite interfaces has also been varied by the choice of the surface treatment for the aluminium alloy layers prior to manufacturing the FML. The various types of FMLs have firstly been 
subjected to quasi-static four-point flexural bend tests to determine their flexural properties and secondly to high-velocity impact loading to study both their deformation behaviour and their perforation resistance. The main conclusions are:

- For the quasi-static flexural-bending tests, the initial stiffness of the surface-treated FML specimens, where a chromic acid etch was employed for the aluminium alloy layers to give relatively good adhesion to the GFRP composite layers, was higher than for the FML specimens which were manufactured without any such surface treatment, where relatively poor adhesion is present at the metal/composite interfaces.

- The strength and energy absorption associated with the quasi-static flexural-bending tests were very significantly higher for the FML specimens which were manufactured using the highest yield strength aluminium alloy, and when employing a chromic acid etch surface treatment for the aluminium alloy prior to manufacture to give good adhesion at the metal/composite interfaces. The strength and energy absorption associated with the quasi-static flexural-bending tests also increased upon increasing the thickness of the FML, which was achieved by employing a greater number of alternating layers of aluminium alloy and GFRP composite in the manufacture of the FML, and again providing that there was relatively good adhesion at the metal/composite interfaces.

- The deformation of the back face of the rear (nonimpacted) aluminium alloy layer of FML panels, when the front face of the FMLs are subjected to a high-velocity impact by the aluminium alloy (25 mm diameter) projectile, was observed using a 3D DIC technique. The 3D DIC results gave a good indication on the effect of the number of aluminium alloy and GFRP composite in the FML panels on the impact behaviour of the FML panels. For example, increasing the number of the aluminium alloy and GFRP composite in FML panels increases the energy absorption of the FML panels.

- For the smaller 10-mm-diameter steel projectiles, the ballistic velocity for the impact perforation threshold of the FMLs was significantly less sensitive to the properties of the aluminium alloy layer than was the case for the quasi-static flexural-bending results. For example, despite the considerable differences that exist between the mechanical properties of the three aluminium alloys, i.e. with respect to their yield strength, tensile strength and ductility, only small differences in the values of the ballistic velocity, $V_{\mathrm{bl}}$, for the projectile to perforate the FML panel, and in the shape of the ballistic curves, were found for the FMLs based upon the three different grades of aluminium alloys.

- On the other hand, increasing the number of aluminium alloy and GFRP composite layers, and thereby increasing the thickness of the FML, significantly enhanced the impact energy absorption of the FML panels for all three grades of aluminium alloy that were employed in the FMLs. As a secondary effect, the values of energy absorption were, in some instances, also somewhat higher as the yield strength and ultimate tensile strengths of the aluminium alloy layer were increased, via the appropriate choice of the grade of the aluminium alloy employed.

- Impact damage occurred in the FML panels in the form of: (a) global bulging (i.e. global plastic deformation) of the panel which eventually led to perforation, (b) perforation via a tearing plastic fracture and local plastic deformation of the aluminium alloy layers (i.e. 'petalling' occurred), and (c) fibre breakage and fracture in the composite layers and (d) delamination of the metal/composite interfaces which in some instances accompanied the perforation of the FML panel. Above the ballistic velocity for perforation, the deformation and damage mechanisms were basically all the same for the FML panels based upon the three grades of aluminium alloy, but varied in extent consistent with the measured values of the impact energy absorption.

- Surface treatment of the aluminium alloy layers prior to manufacture of the FML panel, which increased the relative degree of adhesion between the metal/composite layers, led to a decrease in the extent of the area of delamination between the metal and composite layers during the impact tests. However, surface treatment of the aluminium alloy layers had only a negligible influence on the residual velocity and consequently the energy absorption, especially at initial impact velocities well above the ballistic velocity. This suggested that the contribution of the 
delamination mechanism to the total energy absorption process of the FML panel was relatively low for its perforation by high-velocity projectiles of a small diameter. Thus, the plastic tearing fracture and petalling, which were accompanied by extensive localised plastic deformation of the metal layers, as well as fibre breakage and fracture in the composite layers, were considered to be the main energy-absorbing mechanisms for such tests.

- Increasing the number of composite and metallic layers is very beneficial in resisting high-velocity perforation, and the main mechanisms of energy absorption are plastic tearing fracture and petalling of the aluminium alloy layers, and fibre breakage, delamination and fracture of the GFRP layers.

\section{Acknowledgements}

The authors are grateful to the Turkish Government for the scholarship to support Dr. Cihan Kaboglu during his Ph.D. studies. The strong support from the Aviation Industry Corporation of China (AVIC), First Aircraft Institute (FAI), Beijing Aeronautical Manufacturing Technology Research Institute (BAMTRI) and the Beijing Institute of Aeronautical Materials (BIAM) for Dr. Iman Mohagheghian and Dr. Cihan Kaboglu is also gratefully acknowledged.

Open Access This article is distributed under the terms of the Creative Commons Attribution 4.0 International License (http://creativecommons.org/ licenses/by/4.0/), which permits unrestricted use, distribution, and reproduction in any medium, provided you give appropriate credit to the original author(s) and the source, provide a link to the Creative Commons license, and indicate if changes were made.

\section{References}

[1] Cortes P, Cantwell W (2006) The prediction of tensile failure in titanium-based thermoplastic fibre-metal laminates. Compos Sci Technol 66(13):2306-2316

[2] Vogelesang L, Vlot A (2000) Development of fibre metal laminates for advanced aerospace structures. J Mater Process Technol 103(1):1-5
[3] Gresham J, Cantwell W, Cardew-Hall M, Compston P, Kalyanasundaram S (2006) Drawing behaviour of metalcomposite sandwich structures. Compos Struct 75(1):305-312

[4] Sinmazçelik T, Avcu E, Bora MÖ, Çoban O (2011) A review: fibre metal laminates, background, bonding types and applied test methods. Mater Des 32(7):3671-3685

[5] Zhou J, Guan ZW, Cantwell WJ (2015) The influence of strain-rate on the perforation resistance of fiber metal laminates. Compos Struct 125:247-255

[6] Cortes P, Cantwell WJ (2004) The tensile and fatigue properties of carbon fiber-reinforced PEEK-titanium fibermetal laminates. J Reinf Plast Compos 23(15):1615-1623

[7] Alderliesten R, Rans C, Benedictus R (2008) The applicability of magnesium based fibre metal laminates in aerospace structures. Compos Sci Technol 68(14):2983-2993

[8] Botelho EC, Silva RA, Pardini LC, Rezende MC (2006) A review on the development and properties of continuous fiber/epoxy/aluminum hybrid composites for aircraft structures. Mater Res 9(3):247-256

[9] Vlot A (1996) Impact loading on fibre metal laminates. Int J Impact Eng 18(3):291-307

[10] Reid SR, Zhou G (2000) Impact behaviour of fibre-reinforced composite materials and structures. Elsevier, Amsterdam

[11] Airoldi A, Vesco M, Van Der Zwaag S, Baldi A, Sala G (2009) Damage in GLARE laminates under indentation loads: experimental and numerical results. In: Proceedings of the 17 th international conference on composite materials, 2009. Edinburgh, UK

[12] Lin C, Fatt MSH (2006) Perforation of composite plates and sandwich panels under quasi-static and projectile loading. J Compos Mater 40(20):1801-1840

[13] Sitnikova E, Guan Z, Schleyer G, Cantwell W (2014) Modelling of perforation failure in fibre metal laminates subjected to high impulsive blast loading. Int J Solids Struct 51(18):3135-3146

[14] Zhu S, Chai GB (2012) Low-velocity impact response of fibre-metal laminates-Experimental and finite element analysis. Compos Sci Technol 72(15):1793-1802

[15] Reyes Villanueva G, Cantwell WJ (2004) The high velocity impact response of composite and FML-reinforced sandwich structures. Compos Sci Technol 64(1):35-54

[16] Reyes Villanueva G, Cantwell WJ (2000) The mechanical properties of fibre-metal laminates based on glass fibre reinforced polypropylene. Compos Sci Technol 60(7):1085-1094

[17] Carrillo JG, Cantwell WJ (2009) Mechanical properties of a novel fiber-metal laminate based on a polypropylene composite. Mech Mater 41(7):828-838 
[18] Dhaliwal GS, Newaz GM (2016) Experimental and numerical investigation of flexural behavior of carbon fiber reinforced aluminum laminates. J Reinf Plast Compos 35(12):945-956

[19] Langdon GS, Lemanski SL, Nurick GN, Simmons MC, Cantwell WJ, Schleyer GK (2007) Behaviour of fibre-metal laminates subjected to localised blast loading: part I-experimental observations. Int J Impact Eng 34(7):1202-1222

[20] Lemanski SL, Nurick GN, Langdon GS, Simmons MC, Cantwell WJ, Schleyer GK (2007) Behaviour of fibre metal laminates subjected to localised blast loading-Part II: quantitative analysis. Int J Impact Eng 34(7):1223-1245

[21] Vlot A (1993) Impact properties of fibre metal laminates. Compos Eng 3(10):911-927

[22] Santiago R, Cantwell W, Alves M (2017) Impact on thermoplastic fibre-metal laminates: experimental observations. Compos Struct 159:800-817

[23] Caprino G, Spataro G, Del Luongo S (2004) Low-velocity impact behaviour of fibreglass-aluminium laminates. Compos A Appl Sci Manuf 35(5):605-616

[24] Asaee Z, Shadlou S, Taheri F (2015) Low-velocity impact response of fiberglass/magnesium FMLs with a new 3D fiberglass fabric. Compos Struct 122:155-165

[25] Hoo Fatt MS, Lin C, Revilock DM Jr, Hopkins DA (2003) Ballistic impact of GLARE ${ }^{\mathrm{TM}}$ fiber-metal laminates. Compos Struct 61(1-2):73-88

[26] Compston P, Cantwell WJ, Jones N (2002) Influence of loading rate on the interfacial fracture toughness of a polyamide-based fiber-metal laminate. J Mater Sci Lett 21(5):383-386

[27] Abdullah MR, Cantwell WJ (2006) The impact resistance of polypropylene-based fibre-metal laminates. Compo Sci Technol 66(11-12):1682-1693

[28] Reid SR, Wen HM (2000) Perforation of FRP laminates and sandwich panels subjected to missile impact. Impact behaviour of fibre-reinforced composite materials and structures. Woodhead Publishing, Sawston, pp 239-279

[29] Chai GB, Manikandan P (2014) Low velocity impact response of fibre-metal laminates - a review. Compos Struct 107:363-381

[30] Majzoobi GH, Azadikhah K, Nemati J (2009) The effects of deep rolling and shot peening on fretting fatigue resistance of Aluminum-7075-T6. Mater Sci Eng A 516(1-2):235-247

[31] Standard A (2015) D7264 Standard test method for flexural properties of polymer composite materials. American Society for Testing and Materials, Philadelphia

[32] Mohagheghian I, Wang Y, Zhou J, Yu L, Guo X, Yan Y, Charalambides MN, Dear JP (2017) Deformation and damage mechanisms of laminated glass windows subjected to high velocity soft impact. Int J Solids Struct 109:46-62

[33] Aramis (2011) User information-hardware GOM. p 11

[34] Lambert JP, Jonas GH (1976) Towards satndardization of in terminal ballistic testing: $\sim$ velocity representation. Ballistic Research Laboratories, 1976. BRL-R-18522, Aberdeen, Maryland, USA

[35] Bailey C, Bull T, Lawrence A (2013) The bending of beams and the second moment of area. Plymouth Stud Sci 6(2):328-339

[36] Mohagheghian I, McShane GJ, Stronge WJ (2015) Impact perforation of monolithic polyethylene plates: projectile nose shape dependence. Int J Impact Eng 80:162-176

[37] Holmen JK, Johnsen J, Jupp S, Hopperstad OS, Børvik T (2013) Effects of heat treatment on the ballistic properties of AA6070 aluminium alloy. Int J Impact Eng 57:119-133

[38] Mondal C, Mishra B, Jena PK, Kumar KS, Bhat TB (2011) Effect of heat treatment on the behavior of an AA7055 aluminum alloy during ballistic impact. Int $\mathrm{J}$ Impact Eng 38(8-9):745-754 